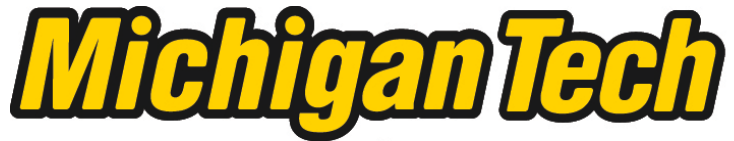 \\ Michigan Technological University Create the Future Digital Commons @ Michigan Tech
}

Dissertations, Master's Theses and Master's Reports - Open

Dissertations, Master's Theses and Master's

Reports

2011

Simulation of four stroke engine cycle for a 4 - valve pentroof engine in KIVA 3VR2

Yu Chen

Michigan Technological University

Follow this and additional works at: https://digitalcommons.mtu.edu/etds

Part of the Mechanical Engineering Commons

Copyright 2011 Yu Chen

\section{Recommended Citation}

Chen, Yu, "Simulation of four stroke engine cycle for a 4 - valve pentroof engine in KIVA 3VR2", Master's report, Michigan Technological University, 2011.

https://doi.org/10.37099/mtu.dc.etds/562

Follow this and additional works at: https://digitalcommons.mtu.edu/etds

Part of the Mechanical Engineering Commons 


\title{
Simulation of Four Stroke Engine Cycle for a 4 -Valve Pentroof Engine in KIVA 3VR2
}

\section{Yu Chen}

\author{
A Report \\ Submitted in partial fulfillment of the requirements for the degree of \\ Master of Science in Mechanical Engineering \\ Department of Mechanical Engineering-Engineering Mechanics \\ Michigan Technological University
}

2011 
This report, "Simulation of Four Stroke Engine Cycle for a 4 -Valve Pentroof Engine in KIVA 3VR2", is hereby approved in partial fulfillment of the requirements for the

Degree of

Master of Science in Mechanical Engineering

Department of Mechanical Engineering - Engineering Mechanics, MTU

Report Advisor:

Dr. Song-Lin Yang

Department Chair:

Dr. William W. Predebon

Date: 


\section{ACKNOWLEDGEMENTS}

First of all I would like to thank my academic advisor, Dr. Song-Lin Yang, who encouraged me to pursue this research in graduate studies and guided me throughout my Master's degree. I cherish all the invaluable knowledge that I gained from him.

I would also like to thank Dr. Seong-Young Lee and Dr. Jim. Hwang for serving in my defense committee who provided all their support in completing my report with their valuable suggestions.

Last but not least, I would thank my parents and family who gave me immense support which helped me to overcome every hurdle and to succeed; also I extend my thanks to all my friends at MTU who added colors to my graduate student life. 


\begin{abstract}
The main purpose of this project is to understand the process of engine simulation using the open source CFD code called KIVA. This report mainly discusses the simulation of the 4-valve Pentroof engine through KIVA 3VR2. KIVA is an open source FORTRAN code which is used to solve the fluid flow field in the engines with the transient $2 \mathrm{D}$ and $3 \mathrm{D}$ chemically reactive flow with spray. It also focuses on the complete procedure to simulate an engine cycle starting from preprocessing until the final results. This report will serve a handbook for the using the KIVA code.
\end{abstract}




\section{Table of Contents}

Simulation of Four Stroke Engine Cycle for a 4 -Valves Pentroof Engine in KIVA 3VR2 .............1

LIST OF TABLES

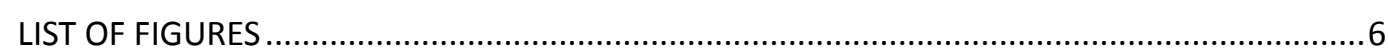

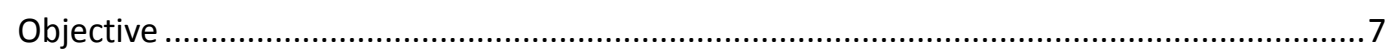

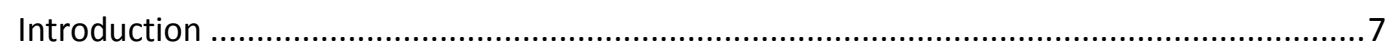

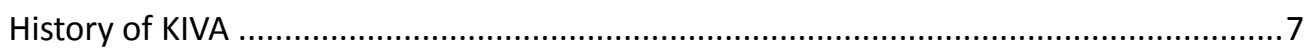

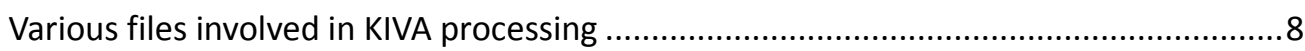

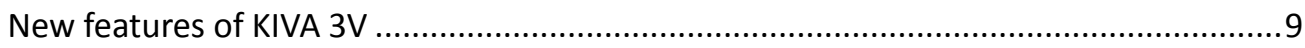

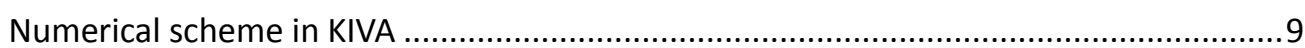

Procedure to run KIVA3V using the compiler COMPAQ Visual Fortran...........................10

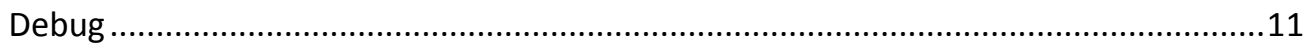

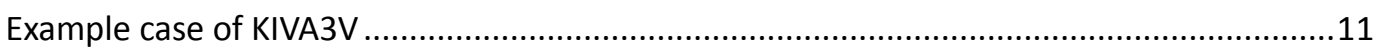

Brief introduction of real engine cycle and ideal Otto cycle .......................................11

Four Valves Pent-roof Engine (3D): ...................................................................

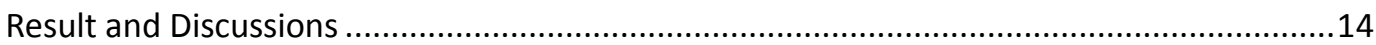

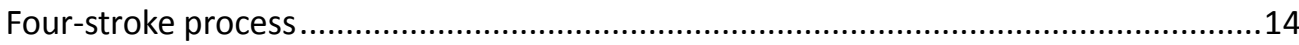

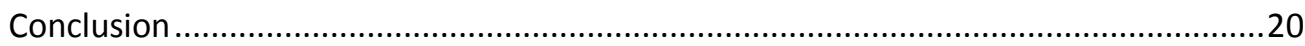

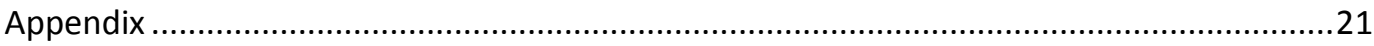

Appendix A-IPREP

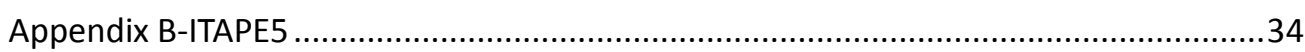

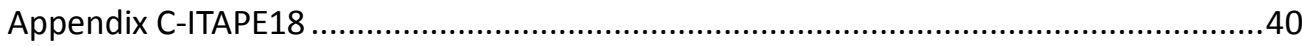

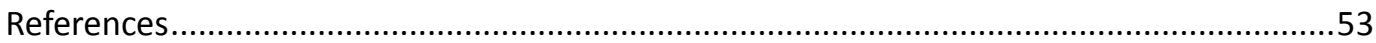




\section{LIST OF TABLES}

Table 1 - Dimensions of engine

Table 2 - Ignition parameters

Table 3 - Ignition location parameters

Table 4 - Injection parameters

\section{LIST OF FIGURES}

Figure 1 - Otto Cycle

Figure 2 - Temperature contour of intake stroke

Figure 3 - Temperature contour of compression stroke

Figure 4 - Temperature contour of combustion

Figure 5 - Temperature contour of flame extend

Figure 6 - Temperature contour of exhaust stroke

Figure 7 - Pressure contour of compression stroke

Figure 8 - Pressure contour of combustion stroke

Figure 9 - Pressure contour of exhaust stroke 


\section{Objective}

The main objective of this project is to understand the process of engine simulation using the open source CFD code called KIVA. This report mainly discusses the simulation of the 4-valve Pentroof engine through KIVA 3VR2. KIVA is an open source FORTRAN code which is used to solve the fluid flow field in the engines with the transient $2 \mathrm{D}$ and $3 \mathrm{D}$ chemically reactive flow with spray. It also focuses on the complete procedure to simulate an engine cycle starting from preprocessing until the final results. This report will serve a handbook for the using the KIVA code.

\section{Introduction}

About $90 \%$ percent of the energy used by human being is from combustion and causes severe pollution. So improving the combustion process in order to reduce the pollution has been a hot topic in auto industries for several years. However, combustion is typically a complicated process. If all the analysis relies only on the experimental researches carried out, it is very costly and practically impossible to resolve every single problem, especially when multiple parameters are taken into consideration. After the development of high performance computers and numerical schemes, the computational analysis of combustion process becomes possible and it saves lots time and money for the auto industries. KIVA is one such program which is widely used in CFD simulation of engine. It is written in FORTRAN.

\section{History of KIVA}

As we know, KIVA code is not accomplished by an action, there is a long way before KIVA code became mature. The first KIVA code was introduced during early 80's. However, until 1985, KIVA was not offered to the public and was developed based on a finite volume method which is called the ALE (arbitrary Lagrangian- Eulerian) method. In 1989, the new version, KIVA II was released. After the improvement, the computing power and computing efficiency have made a remarkable progress and KIVA was soon accepted by the auto industry.

In later version, KIVA 3, which was released in 1993, development was made so that the KIVA code could compute complex geometry. In order to improve the computing efficiency and enhance the ability of dealing with the complex fluid field, the block-structured mesh was introduced into the code. By introducing the block-structured mesh, KIVA3 helps us to split the complex geometries into small, 
regular, simple blocks. Another novelty is that from KIVA3, the pre-processor and the post-processor are split from the main program.

In the later version, KIVA $3 \mathrm{~V}$ represents a significant positive increment in capability by introducing an effective model for intake and exhaust valves. The valve model is a remarkable extension which valves are treated as solid objects that move through the mesh, using the same 'snapper' technique as for piston motion. Combined with the earlier snappers 'SNAPB' and 'SNAPT' which are used in the simulation of piston movement, two other new snappers, 'SNAVTOP' and 'SNAPVFCE' were used as snappers for valves. This effective approach to modeling moving valve became available. In this version, KIVA has matured to where it can be applied to full-engine-cycle calculation.

In the updated version KIVA $3 \mathrm{~V}$ Release 2, the most important extension is that we can now define the number of fuel-injections per engine cycle. This process is achieved through changing the parameter 'NUMINJ' in 'ITAPE5'.

K3PREP is the pre-processor. The pre-processor generates the grid/mesh for the given geometry in the form of an output file called 'OTAPE17' which will be used in the KIVA $3 \mathrm{~V}$ hydro-code after being renamed as 'ITAPE17'. The other output files of the flow solver are 'OTAPE8', 'OTAPE9' and 'OTAPE12'.

KIVA $3 \mathrm{~V}$ is the flow solver which is a block-structured program for 3-D fluid flows with valves, chemical reactions, and fuel sprays. The input files are 'ITAPE5' 'ITAPE17' 'ITAPE18'. The output files of the flow solver are 'OTAPE8', 'OTAPE9', 'OTAPE12,' PLOTGMV files and 'DAT.' files. All these output and input files will be introduced below.

The post-processor can be 3DKIVA3V or 2DKIVA3V. Its function is to generate the result and contour files. Another way to get the simulation contours is by using the software 'TECPLOT'. We can open the 'DAT' files with it, so that we can get the contours of temperature, pressure, velocity and density directly. Also we can load the data file 'OTAPE X' and regulate the XY axis to get the graphs we want.

\section{Various files involved in KIVA processing}

- IPREP: It is one of input files to the 'K3PREP.' It is used to define the number, location and shape of the block and the relationship among the blocks in the grid region, i.e., reshaping procedure and direction. It also determines the boundary conditions;

- ITAPE5: It contains the engine's essential parameter, initial condition, spray parameter, combustion composition, and the duration of ignition. It also provides other input data needed for simulation, such as duration of simulation time, tolerance of computation; 
- ITAPE18: The input file consists of the valves lift information, i.e. valve lift according to crank angle;

- COMPREP.I, COMFUEL.I, COMKIVA.I, and COMPOST.I: These are common file blocks.

- OTAPE17: It is generated by K3PREP and it contains the mesh data of the given geometry. For example, the grid coordinates(x, y, z), the six nearby grid's connecting data, the cell and vertex flags, F and FV, the connectivity arrays for a given cell vertex. It will be renamed as 'ITAPE17' before being provided to the flow solver;

- 3DKIVA or 2DKIVA: The main program files of the post-processor, which control the parameter of the contours or plots. When the dimension of simulation is 2 , 2DKIVA is used. When the dimension of simulation is 3, 3DKIVA is used;

- OTAPE8: It records the data at specific times during the calculation. When the program suspends and restarts, it will become the input file after being renamed as 'ITAPE7';

- OTAPE9: The output file of flow solver that contains the data of the flow field. Usually, after being renamed as 'ITAPE9,' it became the input file of the post-processor;

- OTAPE11 and OTAPE12: The output files which record the running history. It record all important steps;

- DAT.DYNAMIC: It contains the cylinder dynamic data, such as momentum, turbulent kinetic energy, etc.;

- DAT.THERMO: It contains averaged cylinder thermodynamic data, such as pressure, temperature, density, volume and mass;

- DAT.INJECT: It contains fuel injection data, such as the amount of fuel injection by volume and by mass;

- DAT.TURB: It contains averaged turbulent parameters, such as turbulent kinetic energy $(\mathrm{k})$, dissipation rate $(\varepsilon)$, viscosity, etc.

\section{New features of KIVA 3V}

1. The valve model is extended from the previous version, KIVA3, treating valves as solid objects that move through the mesh, using the same "snapper" technique.

2. The new vertex flag array, IDFACE, is introduced into ITAPE17. It is related to valves. If the valve model is used, KIVA3V requires the lift data from the input file ITAPE18.

3. In the fuel library, we have two more new fuel options. The fuel library is extended with natural gas and dimethyl ether (DME).

4. In release 2, we have an extended option 'NUMINJ' in 'ITAPE5,' which defines the number of fuel-injection per engine cycle.

\section{Numerical scheme in KIVA}

The numerical scheme which is used in KIVA is based on the Arbitrary 
Lagrangian-Eulerian (ALE) method. We divided the calculation cycle into 3 steps/phases. In the first step/phase the codes calculates not only the spray droplet collision and oscillation terms but also the mass and energy source terms which are due to the chemistry and spray. There are other source terms related quantities in the governing equations that are solved in this stage. They are mass density equations with only species and continuity terms, momentum equation, cell face normal velocities, momentum equation, cell face normal velocities, volume change equation, internal energy equation without convection terms, and $\mathrm{k}-\varepsilon$ equations.

In the second phase, by the means of solving the governing equations in a coupled, implicit fashion with individual equations sequentially, we can calculate the acoustic mode terms, spray momentum source term, diffusion terms, and the remaining source term in $\mathrm{k}-\varepsilon$ equations. It is similar to the SIMPLE type procedure with individual equations solved using the conjugate residual method.

In the third phase, the flow field is frozen and the moving boundary is reshaped onto a new computational mesh. The third step calculates the convective transport associated with the moving mesh from the second phase to the third phase. This phase is also called rezone phase. This step is accomplished in a sub-cycled, fully explicit fashion. Two convective numerical schemes are available in this step, quasi-second-order upwind and partial donor cell.

\section{Procedure to run KIVA3V using the compiler COMPAQ Visual Fortran}

\section{Pre-processor}

1. Create a new folder which contains K3PREP.F, COMPREP.I, IPREP FADATE.F, UTILITY.F and PLOTGHOST.F.

2. Open the Visual Fortran and run the K3PREP.F with compiling the files COMPREP.I, IPREP, FADATE.F, UTILITY.F and PLOTGHOST.F. And then set the floating point to double accuracy and disable the run time array. The procedure is project $\rightarrow$ settings $\rightarrow$ fortran. These settings are required for any KIVA cases.

3. An output file known as otape 17 will be generated.

\section{Hydro Code}

1. Renamed 'OTAPE17' to 'ITAPE17'.

2. Create a new folder which contains COMFUEL.I, COMKIVA.I, KIVA3.F, FDATE.F, UTILITY.F and SECOND.F, ITAPE5 ITAPE18 and ITAPE17.

3. The output files for the hydro code are OTAPE9, OTAPE12. DAT files and GMV files.

4. As mentioned in previous paragraph, the OTAPE12 and OTAPE8 files are the 
history files. OTAPE 12 contains the history of the entire executing process while OTAPE8 is mainly use for continuous run.

\section{Post Processor}

1. OTAPE9 is mainly for user that who is using other post processing software.

2. The data file in the four DAT files can also be read by other software, such as TECPLOT.

\section{Debug}

Some settings need to be made before executing the main program. Fortran data and the runtime have to be modified. Both of these parameters are under the Fortran settings. User needs to change the 'Default Real Kind' to 8, which originally is 4. It is because the calculation accuracy of KIVA should be double precision, however, on PC, the default setting is single precision. As for runtime, "the array and string bounds" need to be disabled simply because FORTRAN 77 does not support the dynamic arrays.

The output file OTAPE12 contains the results of all parameters after running the flow solver program KIVA3V. Normally, OTAPE12 has all the parameters that showed in ITAPE5 and the numerical value of every parameter in OTAPE12 should be identical to the corresponding parameter in ITAPE5. If it is not, we have to go back to the KIVA3V main program to debug. We may need the help of the epilog to solve this problem.

\section{Example case of KIVA3V}

'Four Valves Pent-roof Engine' example case was used for this project. The example case was run with combustions and without combustion mode. In other words, the case with combustion mode will include chemical reaction in the cylinder whilst the other one does not. The results were then being compared after converting the output files for using Tecplot.

\section{Brief introduction of real engine cycle and ideal Otto cycle}

\section{SI engine four-stroke cycle}

Comment: The crank angle (CA) of a four strokes cycle is 720 .

1. Intake stroke: It is started with the piston at top dead center (TDC) and ends with the piston at bottom center (BDC). It draws fresh air-fuel mixture into the cylinder;

2. Compression stroke: It happens when both valves are closed and the air-fuel 
mixture is compressed to a small fraction of its initial volume. Toward the end of the compression stroke, the spark ignites the compressed mixture;

3. Power stroke: It starts with the piston at TDC and ends at BDC. Because of the combustion of the air-fuel mixture after ignition, the high-temperature and high-pressure gases push the piston down and force the connection rod to rotate;

4. Exhaust stroke: It starts with the piston at BDC and ends at TDC. In this process, the remaining burned gases exit the cylinder through the exhaust valve. At the end of the exhaust stoke, i.e. the piston approaches the TDC, the inlet valve will open and the next cycle starts;

About the crank angles of open and closed valves

1. To increase the mass inducted, the inlet valve opens shortly before the intake stroke starts (-10ATDC) and closes after it ends (240CAD);

2. The exhaust valve opens before the piston reaches BDC during the power stroke (480CAD) and closes after the piston reaches TDC during the exhaust stroke(-10ATDC);

\section{Ideal Otto four -strokes cycle}

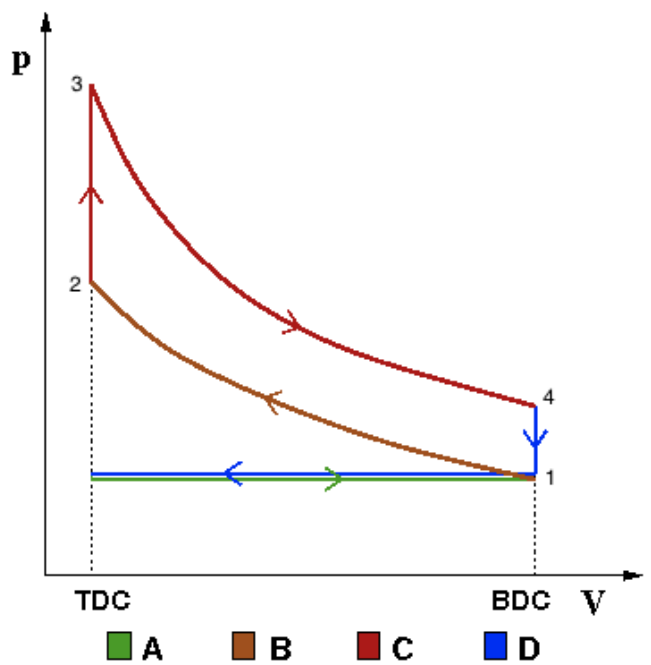

Figure 1-Otto Cycle [4]

Process 1-2(Isentropic compression):

Compression stroke: Piston moves from BDC to TDC and an air-fuel mixture is compressed isentropically through compression ratio $\mathrm{V}_{1} / \mathrm{V}_{2}$. Generally the compression ratio is around 9-10:1 $\left(\mathrm{V}_{1}: \mathrm{V}_{2}\right)$ for a typical automobile.

Process 2-3 (Constant-volume heat addition):

The piston is momentarily at rest at BDC and heat is added to the working fluid at 
constant volume from an external heat source which is brought into contact with cylinder head. The pressure rises and the ratio $\mathrm{P}_{3} / \mathrm{P}_{2}$ is called the "explosion ratio". At this instance the air-fuel mixture is compressed at the top of the compression stroke with the volume is essentially held constant, also known as ignition phase.

Process 3-4(Isentropic expansion):

The high pressure exerts a greater amount of force on the piston and pushes it towards the BDC. Expansion of working fluid takes place isentropically and work is done by the system. The volume ratio V4/V3 is called "isentropic expansion ratio". Mechanically, this is the adiabatic expansion of the hot gaseous mixture in the cylinder head, also known as power stroke.

Process 4-1 (Constant-volume heat rejection):

The piston is momentarily at rest at BDC and heat is rejected to the external sink by bringing it in contact with the cylinder head. The process is so controlled that ultimately the working fluid comes to its initial state 1 and the cycle is completed.

Processe 1-2 involves work to the system and process 3-4 involves work out of the system, but no heat transfer occurs during adiabatic expansion and compression. Processes 2-3 and 4-1 are isochoric (constant volume), therefore heat transfer occurs, but no work is done. No work is done during an isochoric because work requires the movement of piston. When the cylinder volume does not change, no boundary work is produced by the system.

\section{Four Valves Pent-roof Engine (3D):}

The basic specifications of the four valves pent-roof case used for simulation are listed below:

Table 1-Dimensions of engine

\begin{tabular}{|c|c|}
\hline \multicolumn{2}{|c|}{ Specification for the case } \\
\hline Parameters & Values \\
\hline Bore & 9.2 \\
\hline Stroke & 8.5 \\
\hline Squish & 0.115 \\
\hline Connecting rod length & 14.7 \\
\hline RPM & 1500 \\
\hline Hydro/no hydro & Hydro \\
\hline Thsect/sector & $360 / 0$ \\
\hline
\end{tabular}

CAFILM and NCASPEC are the parameters that control the film output based on crank angle. In this simulation, CAFILM is set to a large number so that the 
NCASPEC is the only parameter that controls the film output and the crank angle degrees are set as : -27.0, -15.0, 0.0, 15.0, 30.0, 60.0, 103.0, 180.0, 216.0, 270.0, $345.0360 .0,365,370,375,380,450.0,540.0,609.0,720.0$.

It is important to ensure the mesh quality before running the hydro code. Therefore, it is suggested to the user to turn on the "nohydro" option. When this option is turned on, only piston and valve motions are active, but not the governing equations. This option is useful for check the computational mesh for a complete cycle (0 to $720 \mathrm{CA}$ ).

\section{Result and Discussions}

\section{Four-stroke process}

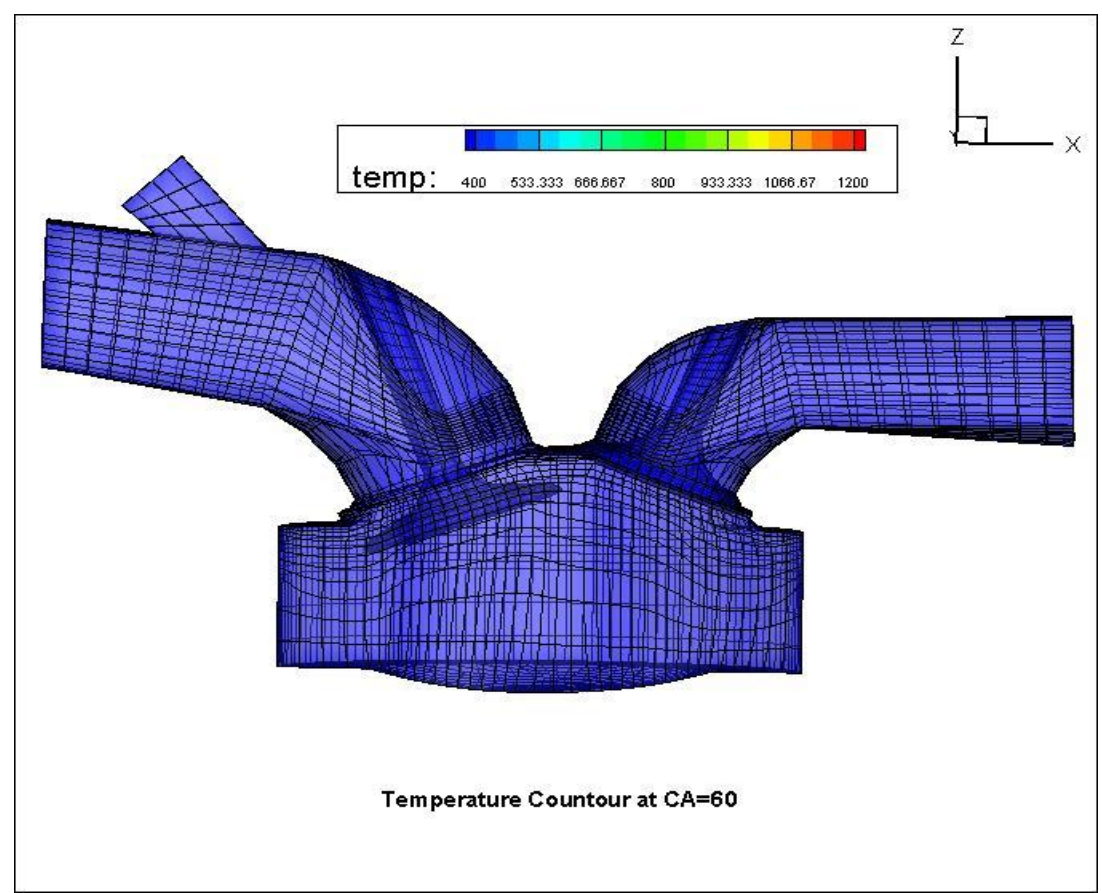

Figure 2-Temperature $(K)$ contour at $C A=60$ 


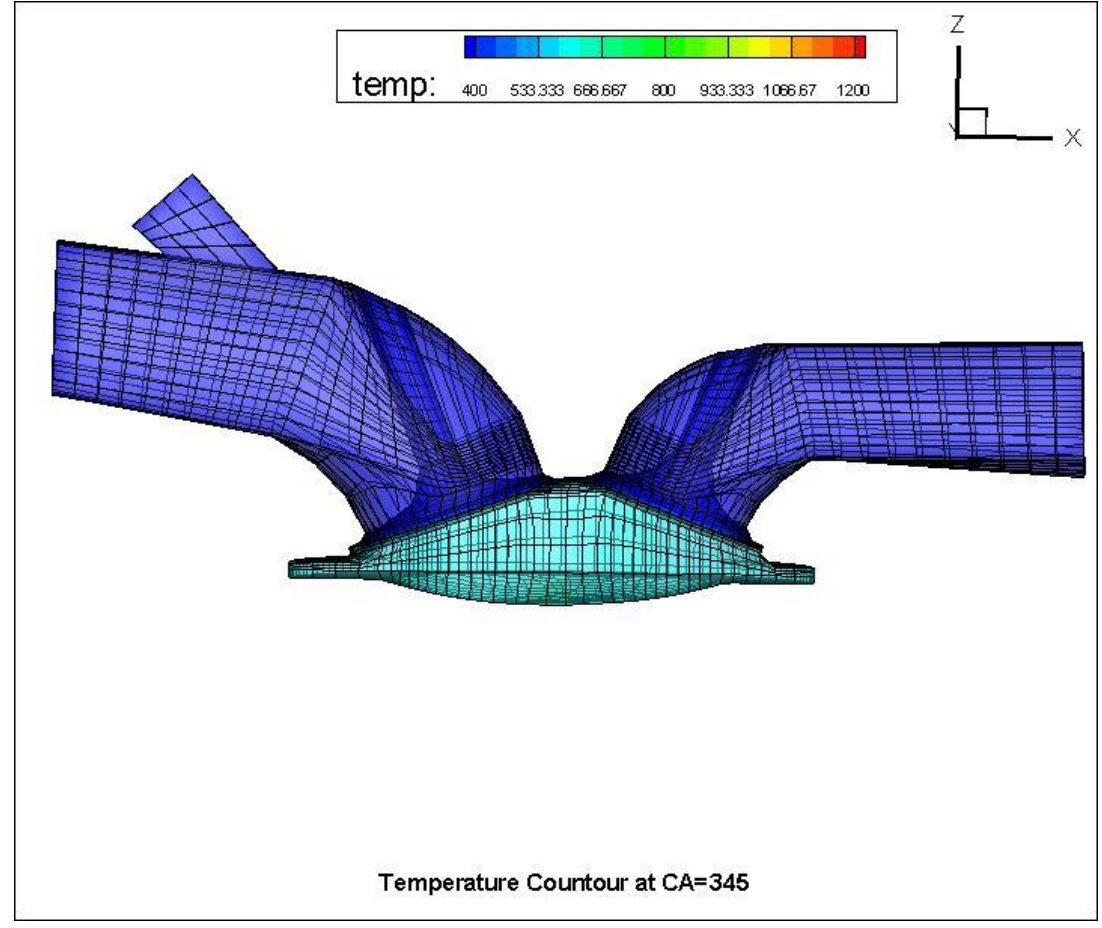

Figure 3-Temperature $(K)$ contour at $C A=345$

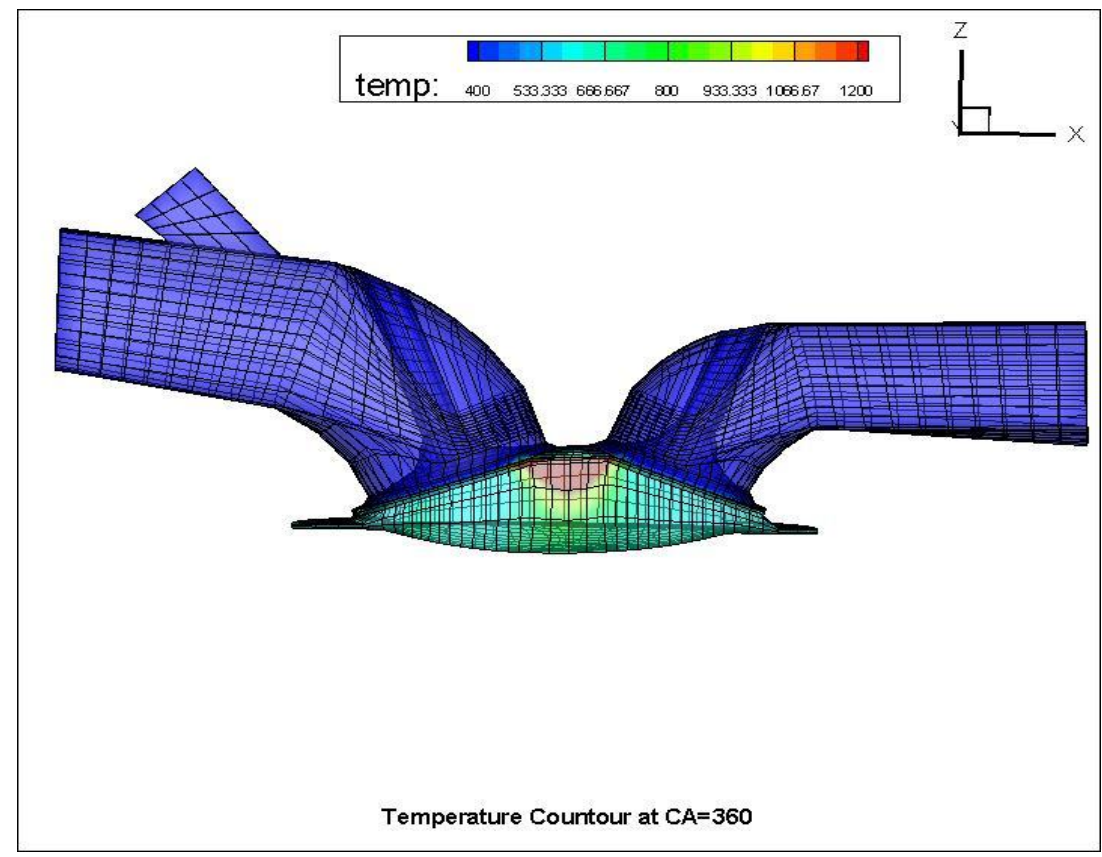

Figure 4-Temperature $(K)$ contour at $C A=360$ 


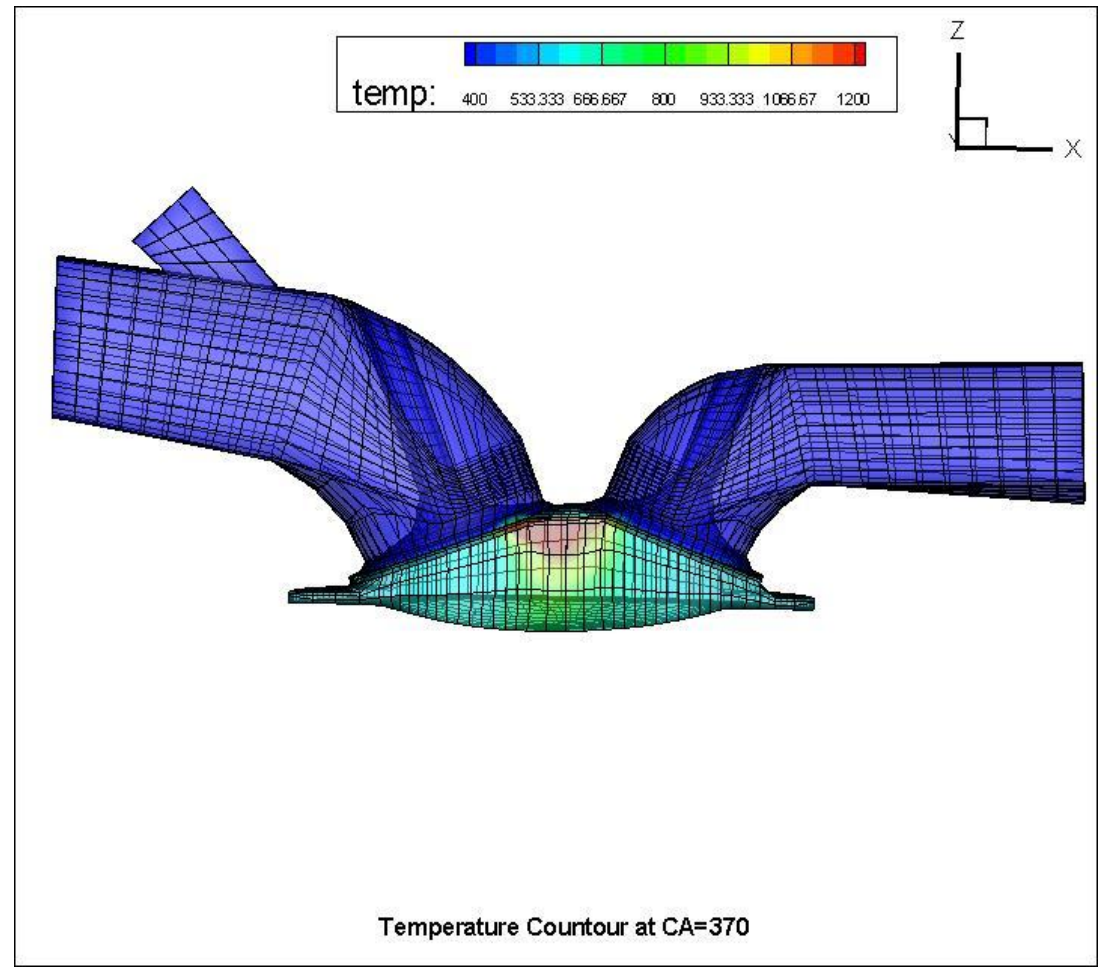

Figure 5-Temperature $(K)$ contour at $C A=370$

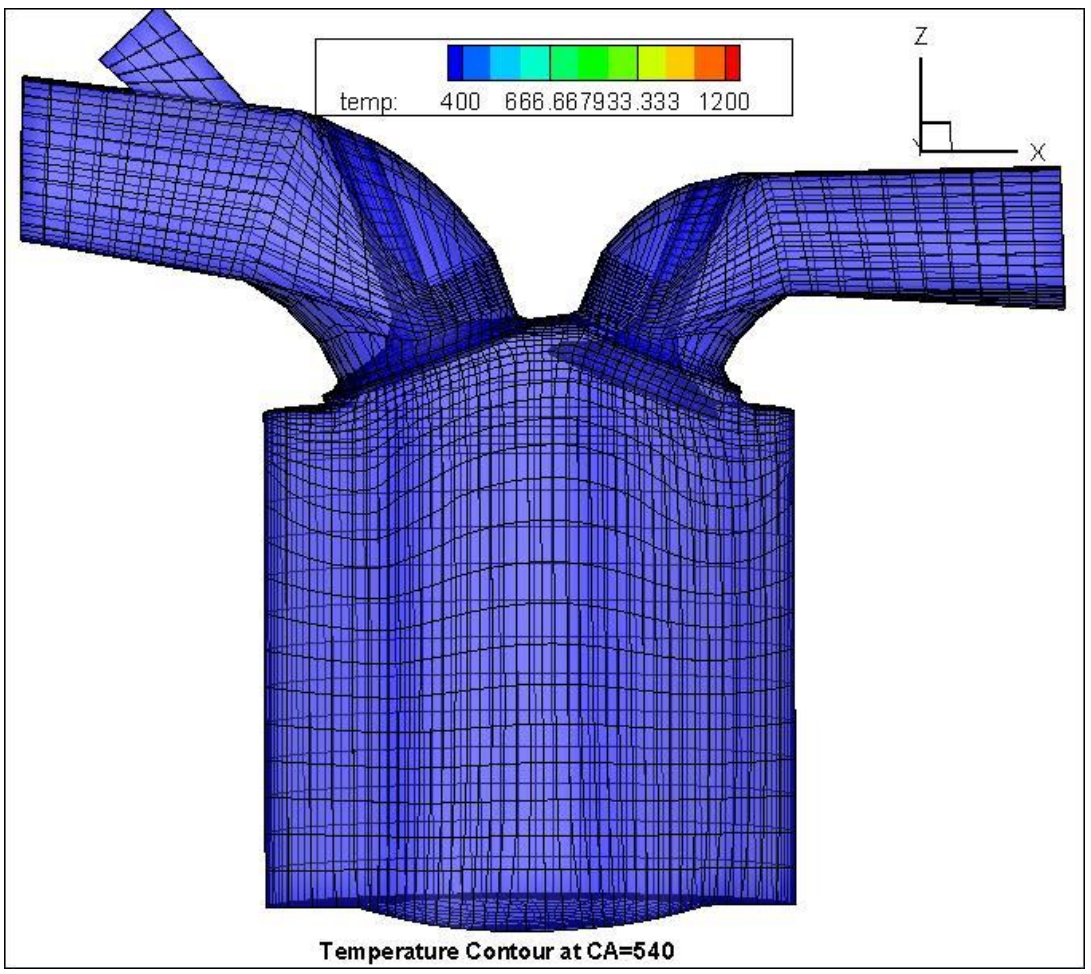

Figure 6-Temperature $(K)$ contour at $C A=540$ 


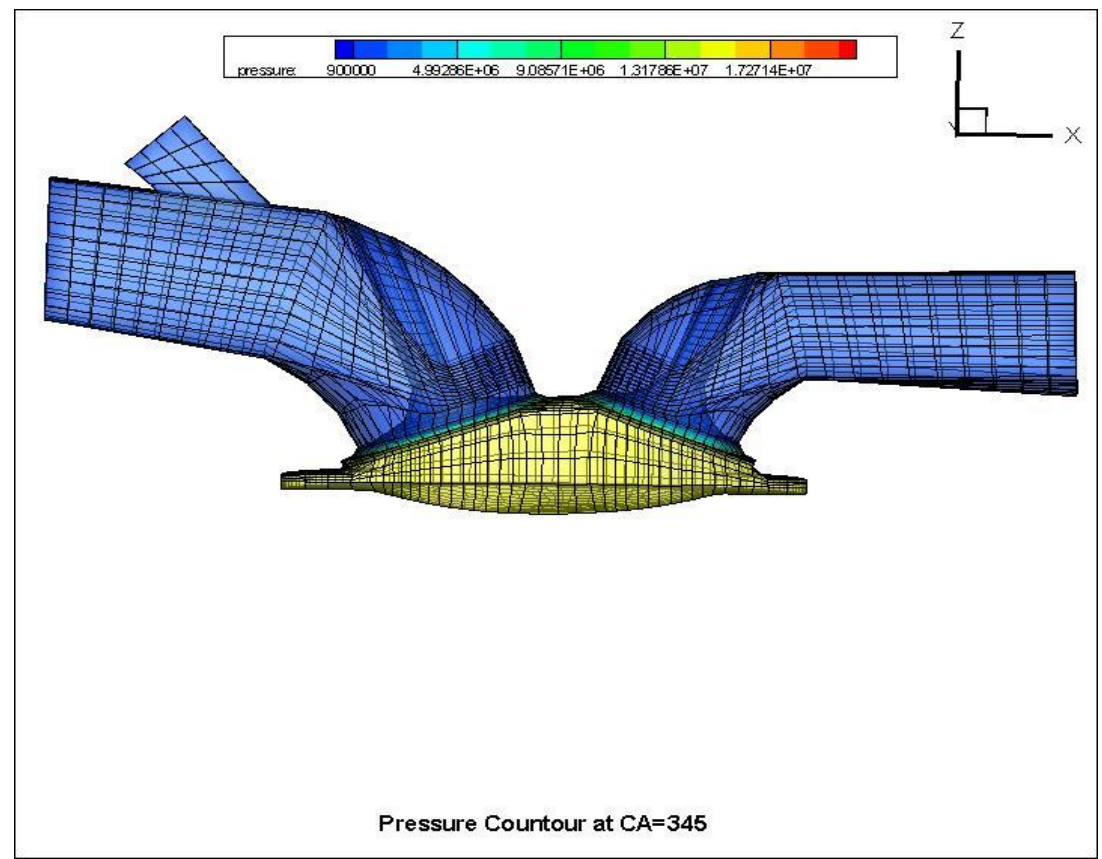

Figure 7-Pressure (dynes/sq. $\mathrm{cm}$ ) contour at CA = 345

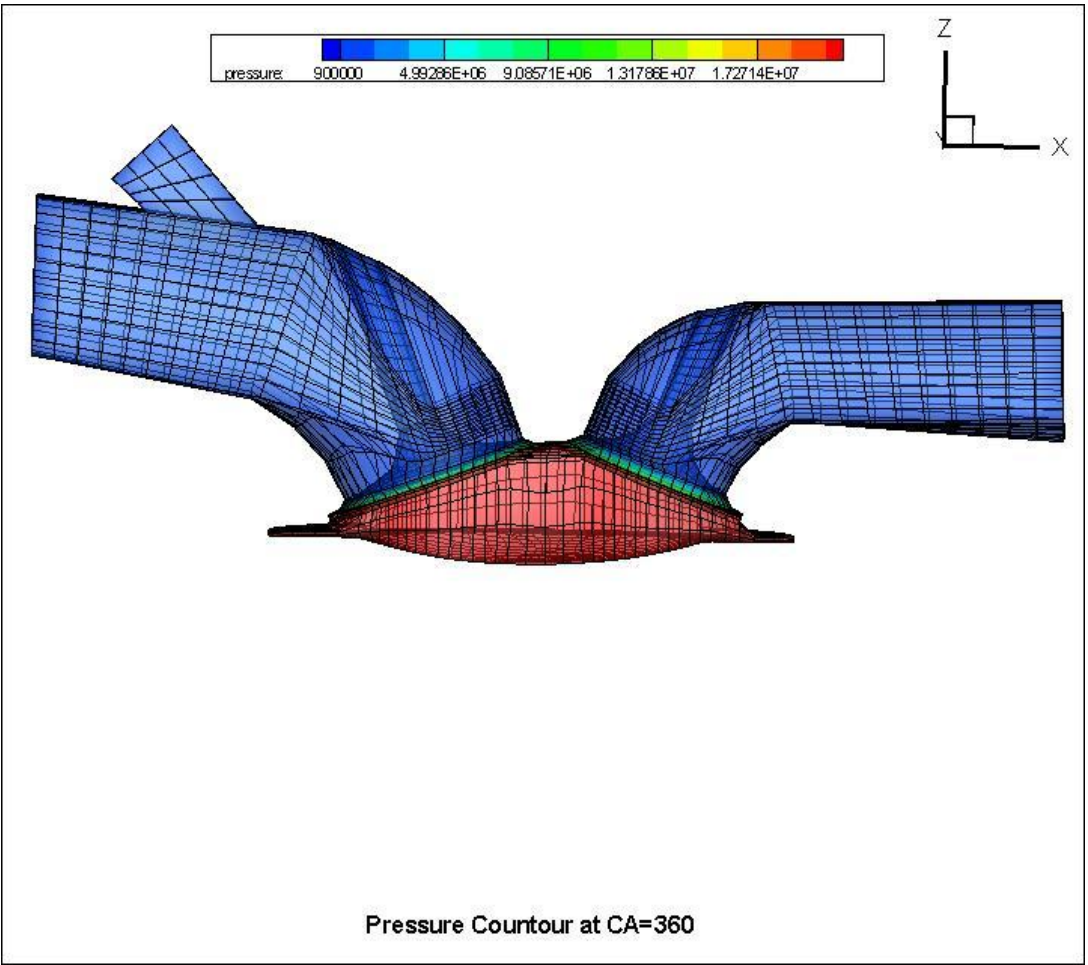

Figure 8-Pressure (dynes/sq. $\mathrm{cm}$ ) contour at CA $=360$ 


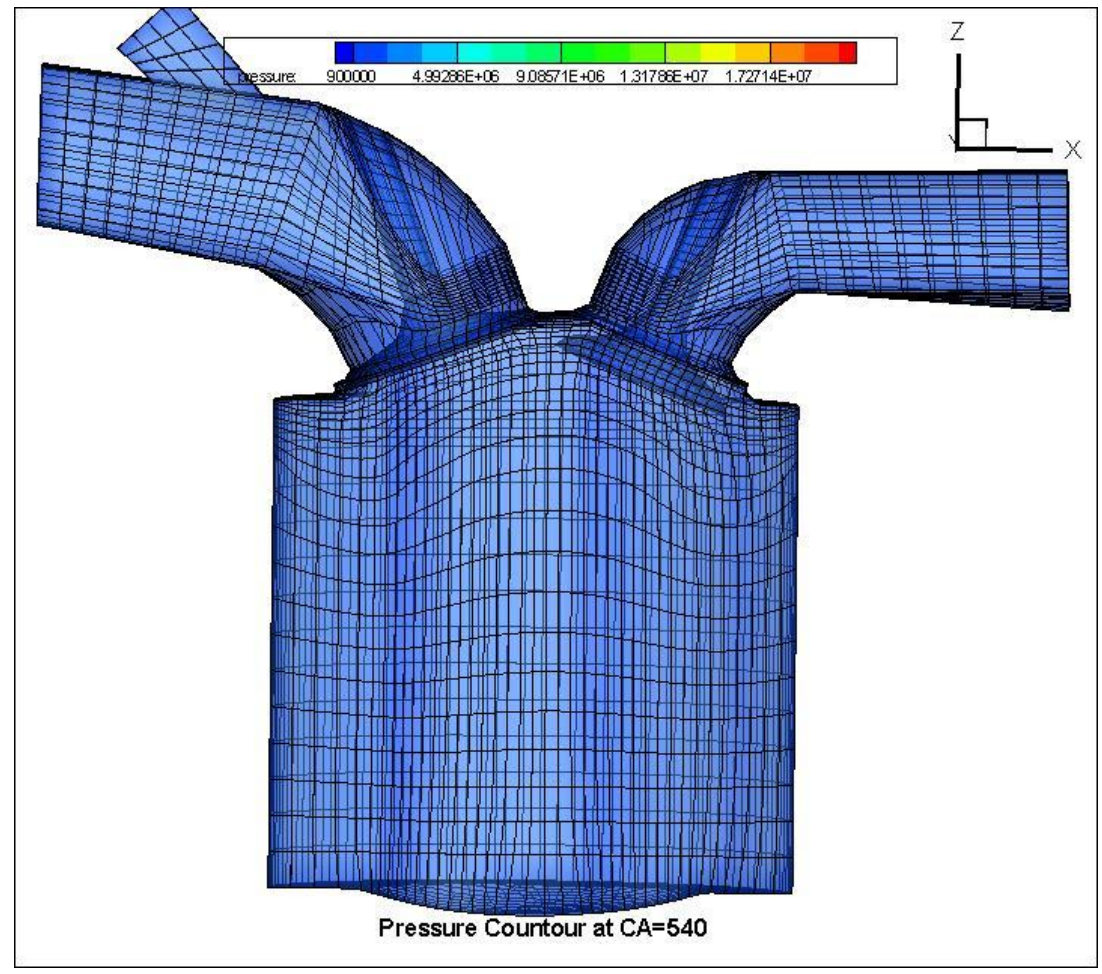

Figure 9-Pressure (dynes/sq. cm) contour at CA $=540$

Figures 2 to 6 show the various property plot comprising of the entire engine cycle for the 4-stroke SI engine. Figure 2 shows the intake stroke with intake valve in open condition and the piston moving from TDC to BDC. As we can see that the temperature is ambient inside the cylinder since the intake is directly from the ambient condition as there is no turbo chargers involved. The 4-valve engine case used is of port injection type and hence the fuel is mixed with the air in the intake port which is injected at $5^{\circ}$ ATDC. Hence during intake stroke, the air-fuel mixture enters into the cylinder. The main objective of this case is to include the fuel injection. The related parameters are T1LINJ, CA1INJ, CADINJ TSPMASS, TNPARC and PULSE. The fuel injection can be controlled either using time or by crank angle and for this project, it is based on crank angle. Parameters CA1INJ and CADINJ determine the beginning of injection and the duration of injection pulse in crank angle degrees respectively. TSPMAS determines spray mass to be injected in grams while PULSE determines spray pattern, in this example case, half-sine injection was chosen. The relevant numbers of parameters are listed below.

Table 2-Ignition parameters

\begin{tabular}{|l|l|}
\hline CA1INJ & 5 \\
\hline CADINJ & 46 \\
\hline TSPMAS & 0.070 \\
\hline TNPARC & 1000 \\
\hline PULSE & 1 \\
\hline
\end{tabular}

Figure 3 and 7 shows the temperature and pressure profile during the end of compression stroke just before ignition. The fuel- air mixture is ignited during end 
stage of compression at 346.5 CAD. We can notice that the temperature and pressure are quite high but still not the maximum of the cycle.

When the piston almost reaches TDC, as show in figures 4 and 8, the pressure of air-fuel mixture reaches almost 10 times than the initial condition and the temperature rises to $600 \mathrm{~K}$. Since we don't have the spark plug in the program, instead we generate heat energy at certain cells to simulate the spark plug. The ignition region is determined by the parameters XIGNL1 XIGNR1 YIGNF1 YIGND1 ZIGNB1 and ZIGNT1 and are listed in table 3

Table 3-Ignition location parameters

\begin{tabular}{|l|l|}
\hline xignl1 & +0.1 \\
\hline xignr1 & +0.45 \\
\hline yignf1 & -0.25 \\
\hline yignd1 & +0.25 \\
\hline zignb1 & 9.5000 \\
\hline zignt1 & 9.9500 \\
\hline
\end{tabular}

In figures 4 and 5, we can find that the temperature is rising rapidly. Figure 5 records the maximum temperature of the cycle just at the beginning of the power stroke. When high energy is generated as a result of simulated spark, the temperature in those raise beyond the TCUT and initiates the chemical reaction. TCUT, TCUTE and the temperature in the cylinder determines the type of chemical reaction to be happening in the cylinder. If the temperature of air-fuel mixture is higher than the temperature set in TCUT but lower than TCUTE, then the chemical reactions will happen and are calculated in kinetic reaction. If the temperature of air-fuel mixture is higher than the temperature in TCUTE, equilibrium reaction will be activated. If the temperature of air-fuel mixture is lower than TCUT, no chemical reaction will activated. The key parameters which control the time and the duration of ignition are T1IGN, TDIGN, CA1IGN and CADIGN. The ignition is controlled by crank angle instead of time for this example case. Parameters CA1IGN and CADIGN determined the beginning of injection and the duration of injection pulse in crank angle degrees. The relevant quantities are listed in table 4.

Table 4-Injection parameters

\begin{tabular}{|l|l|}
\hline TCUT & 800 \\
\hline TCUTE & 1000 \\
\hline CA1ING & 346.5 \\
\hline CADINJ & 10 \\
\hline
\end{tabular}

The figure 6 and 9 describes the end of the power stroke where the exhaust valves are opened and the temperature and pressure is close to the ambient condition but a little higher than the initial conditions. 


\section{Conclusion}

The complete engine cycle has been successfully simulated for the 4-valve pentroof engine case using the KIVA3VR2 code. The results are analyzed for every stroke in the cycle. The temperature and pressure distribution are inside the cylinder. This project provides an overview of all the procedures involved in simulating the engine cycle starting from the pre-processor to analyzing of the finals results. This report could serve as a beginner's handbook to learn using KIVA code for engine simulation. 


\section{Appendix}

\section{Appendix A-IPREP}

K3PREP/100198 4-valve pentroof engine (082096/1135), 052899/1030

$$
\begin{aligned}
& \text { bore } \quad 9.2 \\
& \text { stroke } \quad 8.5 \\
& \text { squish } \quad 0.115 \\
& \text { thsect } 360.0 \\
& \text { nblocks } 36 \\
& \begin{array}{llllllll}
1 & 39 & 34 & 20 & 0 & 2 & 1 & 0
\end{array} \\
& 4.6000 \quad 4.6000-4.6000-4.6000 \quad 4.6000 \quad 4.6000-4.6000-4.6000
\end{aligned}
$$

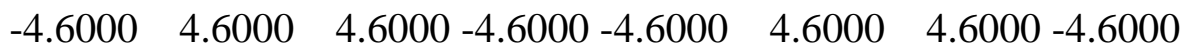

$$
\begin{aligned}
& \begin{array}{llllllll}
0.0 & 0.0 & 0.0 & 0.0 & 8.6150 & 8.6150 & 8.6150 & 8.6150
\end{array} \\
& \begin{array}{rrrrrr}
2.0 & 2.0 & 2.0 & 2.0 & 1.0 & 2.0
\end{array} \\
& \begin{array}{llllll}
-1.0 & -1.0 & -1.0 & -1.0 & 0.0 & -1.0
\end{array} \\
& \begin{array}{llllllll}
2 & 32 & 34 & 1 & 0 & 4 & 1 & 0
\end{array} \\
& 3.6000 \quad 3.6000-3.6000-3.6000 \quad 3.6000 \quad 3.6000-3.6000-3.6000
\end{aligned}
$$

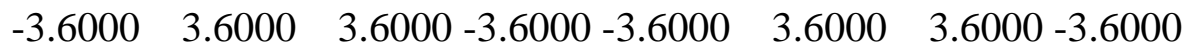

$$
\begin{aligned}
& \begin{array}{llllllll}
8.6150 & 8.6150 & 8.6150 & 8.6150 & 8.6900 & 8.6900 & 8.6900 & 8.6900
\end{array} \\
& \begin{array}{rrrrrr}
2.0 & 2.0 & 2.0 & 2.0 & 4.0 & 4.0
\end{array} \\
& \begin{array}{llllll}
-1.0 & -1.0 & -1.0 & -1.0 & -1.0 & -1.0
\end{array} \\
& \begin{array}{llllllll}
3 & 32 & 34 & 1 & 0 & 4 & 1 & 0
\end{array} \\
& 3.6000 \quad 3.6000-3.6000-3.6000 \quad 3.6000 \quad 3.6000-3.6000-3.6000
\end{aligned}
$$

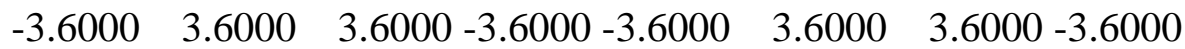

$$
\begin{aligned}
& \begin{array}{llllllll}
8.6900 & 8.6900 & 8.6900 & 8.6900 & 8.7400 & 8.7400 & 8.7400 & 8.7400
\end{array} \\
& \begin{array}{llllll}
2.0 & 2.0 & 2.0 & 2.0 & 4.0 & 2.0
\end{array} \\
& \begin{array}{llllll}
-1.0 & -1.0 & -1.0 & -1.0 & -1.0 & -1.0
\end{array} \\
& \begin{array}{llllllll}
4 & 10 & 10 & 13 & 0 & 5 & 2 & 0
\end{array} \\
& 1.6500 \quad 1.6500-1.6500-1.6500 \quad 1.6500 \quad 1.6500-1.6500-1.6500 \\
& \begin{array}{llllll}
-1.6500 & 1.6500 & 1.6500-1.6500-1.6500 & 1.6500 & 1.6500 & -1.6500
\end{array} \\
& \begin{array}{llllll}
8.7400 & 8.7400 & 8.7400 & 8.740014 .090014 .090014 .090014 .0900
\end{array} \\
& \begin{array}{rrrrrr}
2.0 & 2.0 & 2.0 & 2.0 & 4.0 & 2.0
\end{array} \\
& \begin{array}{llllll}
-1.0 & -1.0 & -1.0 & -1.0 & -1.0 & -1.0
\end{array} \\
& \begin{array}{llllllll}
5 & 10 & 10 & 13 & 0 & 5 & 2 & 0
\end{array} \\
& 1.6500 \quad 1.6500-1.6500-1.6500 \quad 1.6500 \quad 1.6500-1.6500-1.6500 \\
& \begin{array}{llllll}
-1.6500 & 1.6500 & 1.6500-1.6500-1.6500 & 1.6500 & 1.6500-1.6500
\end{array} \\
& 8.7400 \quad 8.7400 \quad 8.7400 \quad 8.740014 .090014 .090014 .090014 .0900 \\
& \begin{array}{rrrrrr}
2.0 & 2.0 & 2.0 & 2.0 & 4.0 & 2.0
\end{array} \\
& \begin{array}{llllll}
-1.0 & -1.0 & -1.0 & -1.0 & -1.0 & -1.0
\end{array} \\
& \begin{array}{llllllll}
6 & 10 & 10 & 10 & 0 & 4 & 2 & 0
\end{array} \\
& -4.0428-4.0428-7.4623-7.4623-2.1342-2.1342-6.45 \quad-6.45 \\
& \begin{array}{llllllll}
0.1000 & 2.7000 & 2.7000 & 0.1000 & 0.1000 & 2.7000 & 2.7000 & 0.1000
\end{array}
\end{aligned}
$$


11.196911 .196913 .179413 .179413 .639713 .639715 .790015 .7900

$$
\begin{aligned}
& \begin{array}{rrrrrr}
9.0 & 4.0 & 2.0 & 2.0 & 2.0 & 2.0
\end{array} \\
& \begin{array}{llllll}
-1.0 & -1.0 & -1.0 & -1.0 & -1.0 & -1.0
\end{array} \\
& \begin{array}{llllllll}
7 & 10 & 10 & 10 & 0 & 4 & 2 & 0
\end{array} \\
& -4.0428-4.0428-7.4623-7.4623-2.1342-2.1342-6.45 \quad-6.45
\end{aligned}
$$$$
-2.7000-0.1000-0.1000-2.7000-2.7000-0.1000-0.1000-2.7000
$$

11.196911 .196913 .179413 .179413 .639713 .639715 .790015 .7900

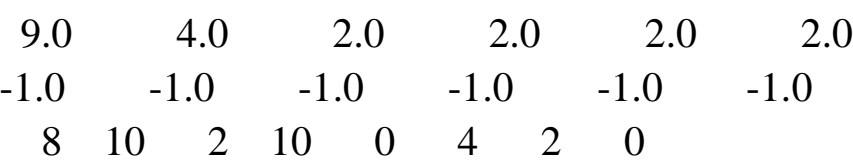

$-4.0428-4.0428-7.4623-7.4623-2.1342-2.1342-6.45 \quad-6.45$

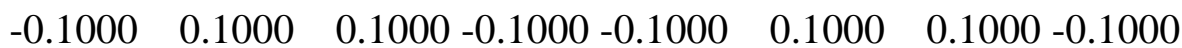

11.196911 .196913 .179413 .179413 .639713 .639715 .790015 .7900

$\begin{array}{rrrrrrrr}9.0 & & 2.0 & & 4.0 & 4.0 & 2.0 & 2.0 \\ -1.0 & -1.0 & -1.0 & -1.0 & -1.0 & -1.0 \\ 9 & 4 & 2 & 4 & 0 & 4 & 2 & 0\end{array}$

$\begin{array}{lllll}-2.9974-2.9974-4.7237 & -4.7237-3.80 & -3.80 & -5.10 & -5.10\end{array}$

$\begin{array}{llllllll}-0.35 & 0.35 & 0.35 & -0.35 & -0.35 & 0.35 & 0.35 & -0.35\end{array}$

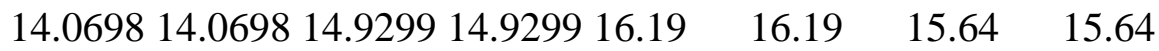

$\begin{array}{cccccc}2.0 & 2.0 & 4.0 & 4.0 & 4.0 & 2.0 \\ -1.0 & -1.0 & -1.0 & -1.0 & -1.0 & -1.0\end{array}$

$\begin{array}{llllllll}10 & 4 & 2 & 4 & 0 & 4 & 2 & 0\end{array}$

$\begin{array}{lllll}-2.9974 & -2.9974-4.7237-4.7237-3.80 & -3.80 & -5.10 & -5.10\end{array}$

$\begin{array}{llllllll}+0.35 & 0.70 & 0.70 & +0.35 & +0.35 & 0.70 & 0.70 & +0.35\end{array}$

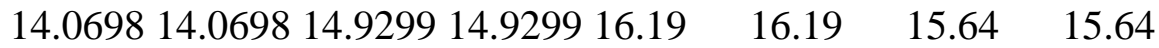

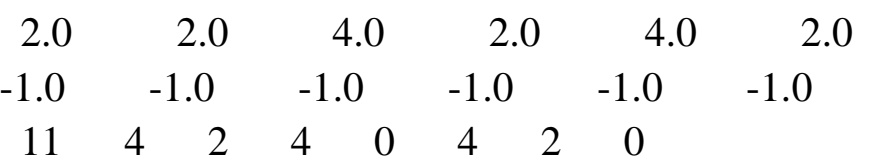

\begin{tabular}{|c|c|c|c|c|c|}
\hline 2.0 & 2.0 & 2.0 & 4.0 & 4.0 & 2.0 \\
\hline 1.0 & -1.0 & -1.0 & -1.0 & -1.0 & -1.0 \\
\hline 1210 & 10 & 0 & 5 & 0 & \\
\hline 1.3500 & 1.3500 & -1.3500 & -1.3500 & 1.3500 & $1.3500-1.3500-1.3500$ \\
\hline-1.3500 & 1.3500 & 1.3500 & -1.3500 & -1.3500 & $1.3500 \quad 1.3500-1.3500$ \\
\hline 8.7400 & 8.7400 & 8.7400 & 8.740 & 012.4650 & 12.465012 .465012 .4650 \\
\hline 2.0 & 2.0 & 2.0 & 2.0 & 4.0 & 2.0 \\
\hline-1.0 & -1.0 & -1.0 & -1.0 & -1.0 & -1.0 \\
\hline $13 \quad 10$ & 10 & 0 & 3 & 0 & \\
\hline 1.3500 & 1.3500 & -1.3500 & -1.3500 & 1.3500 & $1.3500-1.3500-1.3500$ \\
\hline-1.3500 & 1.3500 & 1.3500 & -1.3500 & -1.3500 & $1.3500 \quad 1.3500-1.3500$ \\
\hline 8.7400 & 8.7400 & 8.7400 & 8.740 & 012.4650 & 12.465012 .465012 .4650 \\
\hline 2.0 & 2.0 & 2.0 & 2.0 & 4.0 & 2.0 \\
\hline
\end{tabular}

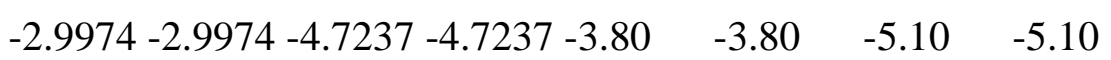

$\begin{array}{llllllll}-0.70 & -0.35 & -0.35 & -0.70 & -0.70 & -0.35 & -0.35 & -0.70\end{array}$

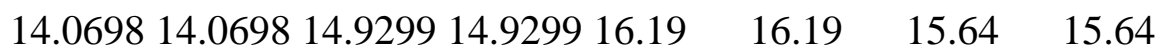




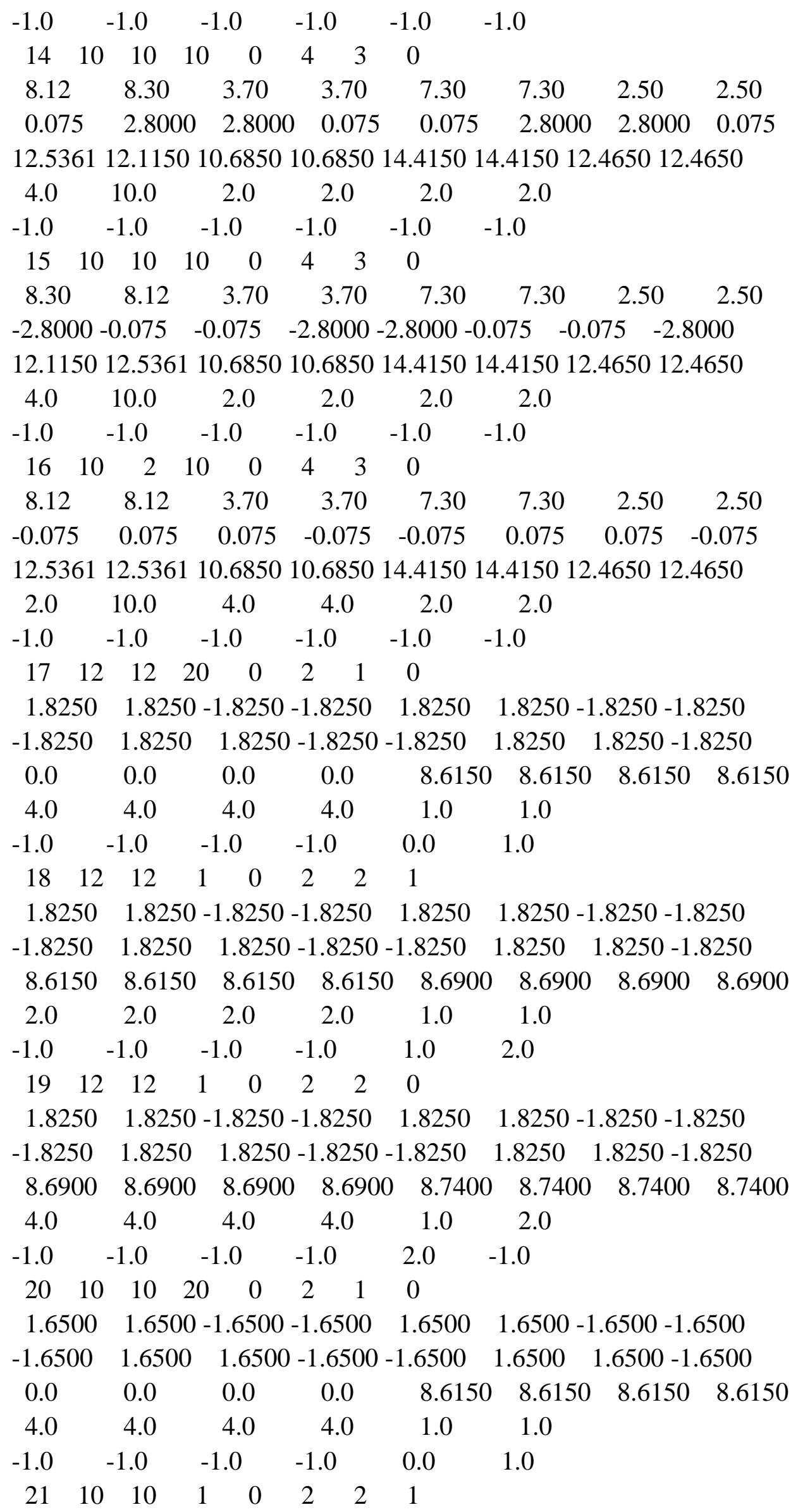




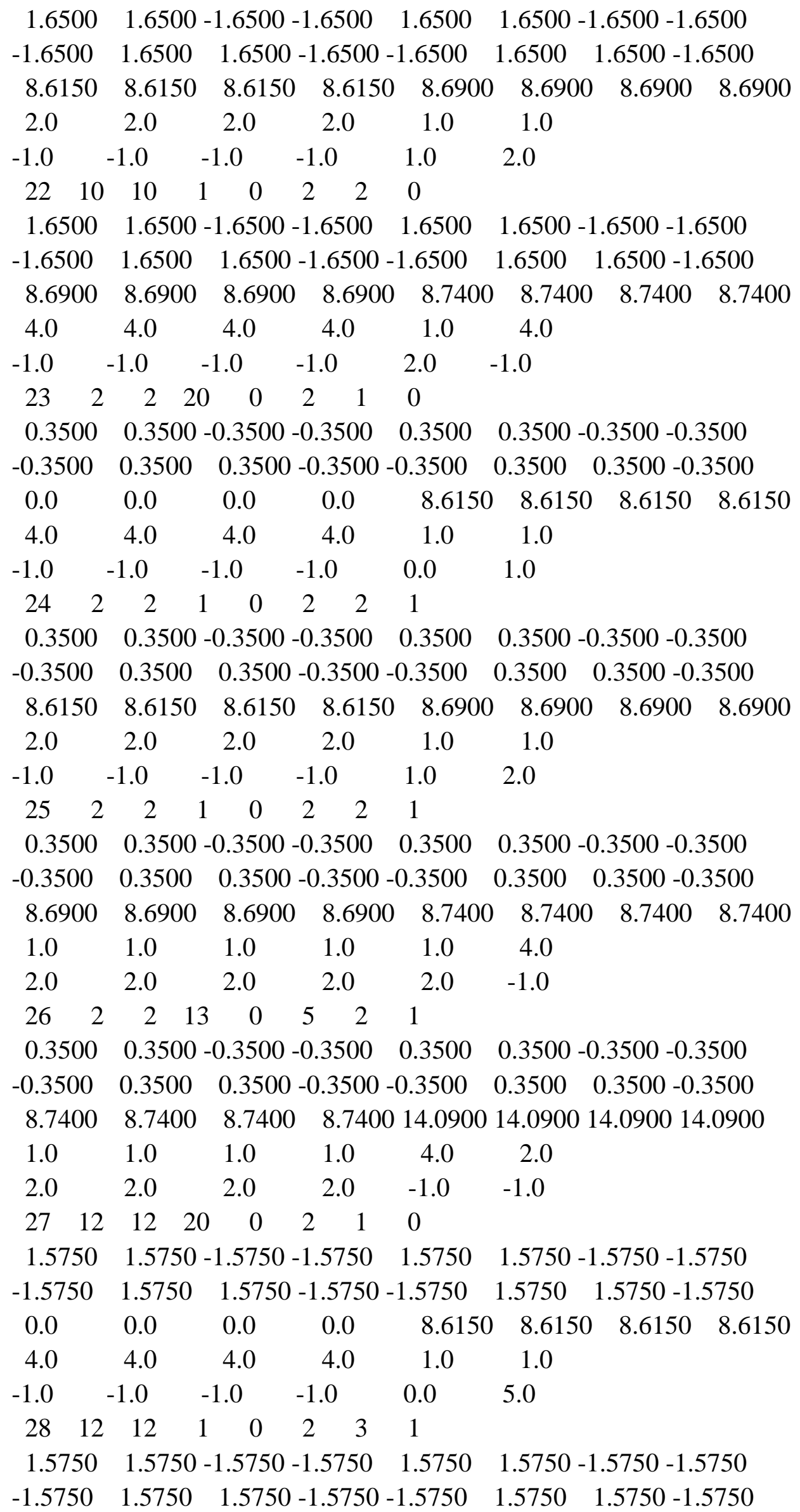




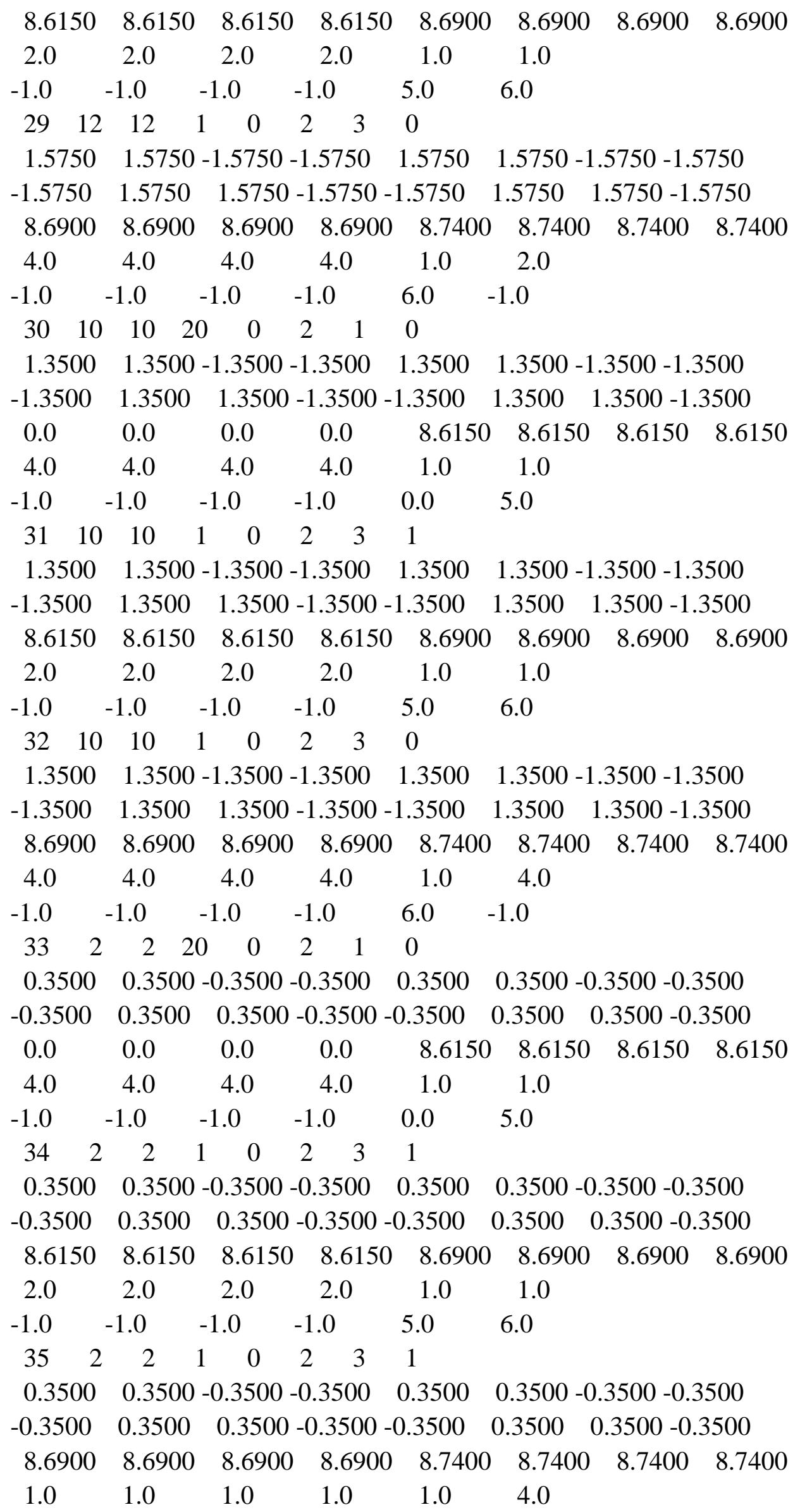




$$
\begin{aligned}
& \begin{array}{llllll}
6.0 & 6.0 & 6.0 & 6.0 & 6.0 & -1.0
\end{array} \\
& \begin{array}{llllllll}
36 & 2 & 2 & 13 & 0 & 5 & 3 & 1
\end{array} \\
& 0.3500 \quad 0.3500-0.3500-0.3500 \quad 0.3500 \quad 0.3500-0.3500-0.3500
\end{aligned}
$$

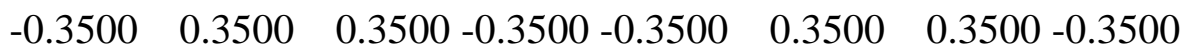

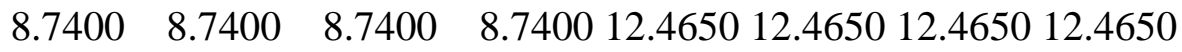

$$
\begin{aligned}
& \begin{array}{rrrrrr}
1.0 & 1.0 & 1.0 & 1.0 & 4.0 & 2.0
\end{array} \\
& \begin{array}{llllll}
6.0 & 6.0 & 6.0 & 6.0 & -1.0 & -1.0
\end{array} \\
& \text { ncopy } 20 \\
& \begin{array}{llll}
17 & 37 & 1 & 2.0
\end{array} \\
& \begin{array}{llll}
18 & 38 & 2 & 2.0
\end{array} \\
& \begin{array}{llll}
19 & 39 & 2 & 2.0
\end{array} \\
& \begin{array}{llll}
20 & 40 & 1 & 2.0
\end{array} \\
& \begin{array}{llll}
21 & 41 & 2 & 2.0
\end{array} \\
& \begin{array}{llll}
22 & 42 & 2 & 2.0
\end{array} \\
& \begin{array}{llll}
23 & 43 & 1 & 2.0
\end{array} \\
& \begin{array}{llll}
24 & 44 & 2 & 2.0
\end{array} \\
& \begin{array}{llll}
25 & 45 & 2 & 2.0
\end{array} \\
& \begin{array}{llll}
26 & 46 & 2 & 2.0
\end{array} \\
& \begin{array}{llll}
27 & 47 & 1 & 2.0
\end{array} \\
& \begin{array}{llll}
28 & 48 & 3 & 2.0
\end{array} \\
& \begin{array}{llll}
29 & 49 & 3 & 2.0
\end{array} \\
& \begin{array}{llll}
30 & 50 & 1 & 2.0
\end{array} \\
& \begin{array}{llll}
31 & 51 & 3 & 2.0
\end{array} \\
& \begin{array}{llll}
32 & 52 & 3 & 2.0
\end{array} \\
& \begin{array}{llll}
33 & 53 & 1 & 2.0
\end{array} \\
& \begin{array}{llll}
34 & 54 & 3 & 2.0
\end{array} \\
& \begin{array}{llll}
35 & 55 & 3 & 2.0
\end{array} \\
& \begin{array}{llll}
36 & 56 & 3 & 2.0
\end{array} \\
& \text { tiltflag } 4 \\
& \begin{array}{lllll}
2 & 2 & -4.6 & 0.0 & 8.614
\end{array} \\
& \begin{array}{lllll}
2 & 3 & 0.0 & +4.6 & 8.614
\end{array} \\
& \begin{array}{lllll}
3 & 2 & -4.6 & 0.0 & 8.614
\end{array} \\
& \begin{array}{lllll}
3 & 3 & 0.0 & +4.6 & 8.614
\end{array} \\
& \text { pentflag } 3 \\
& \begin{array}{lll}
1 & 20 & 22
\end{array} \\
& \begin{array}{lll}
2 & 16 & 18
\end{array} \\
& \begin{array}{lll}
3 & 16 & 18
\end{array} \\
& \text { wedgeflag } 0 \\
& \text { translate } 44 \\
& \begin{array}{llll}
4 & -1.50 & 1.95 & 0.0
\end{array} \\
& \begin{array}{llll}
5 & -1.50 & -1.95 & 0.0
\end{array} \\
& \begin{array}{rrrr}
12 & +1.84 & 1.95 & 0.0
\end{array} \\
& 13+1.84 \quad-1.95 \quad 0.0 \\
& \begin{array}{llll}
17 & -1.50 & 1.95 & 0.0
\end{array}
\end{aligned}
$$




\begin{tabular}{|c|c|c|c|}
\hline 18 & -1.50 & 1.95 & 0.0 \\
\hline 19 & -1.50 & 1.95 & 0.0 \\
\hline 20 & -1.50 & 1.95 & 0.0 \\
\hline 21 & -1.50 & 1.95 & 0.0 \\
\hline 22 & -1.50 & 1.95 & 0.0 \\
\hline 23 & -1.50 & 1.95 & 0.0 \\
\hline 24 & -1.50 & 1.95 & 0.0 \\
\hline 25 & -1.50 & 1.95 & 0.0 \\
\hline 26 & -1.50 & 1.95 & 0.0 \\
\hline 27 & +1.84 & 1.95 & 0.0 \\
\hline 28 & +1.84 & 1.95 & 0.0 \\
\hline 29 & +1.84 & 1.95 & 0.0 \\
\hline 30 & +1.84 & 1.95 & 0.0 \\
\hline 31 & +1.84 & 1.95 & 0.0 \\
\hline 32 & +1.84 & 1.95 & 0.0 \\
\hline 33 & +1.84 & 1.95 & 0.0 \\
\hline 34 & +1.84 & 1.95 & 0.0 \\
\hline 35 & +1.84 & 1.95 & 0.0 \\
\hline 36 & +1.84 & 1.95 & 0.0 \\
\hline 37 & -1.50 & -1.95 & 0.0 \\
\hline 38 & -1.50 & -1.95 & 0.0 \\
\hline 39 & -1.50 & -1.95 & 0.0 \\
\hline 40 & -1.50 & -1.95 & 0.0 \\
\hline 41 & -1.50 & -1.95 & 0.0 \\
\hline 42 & -1.50 & -1.95 & 0.0 \\
\hline 43 & -1.50 & -1.95 & 0.0 \\
\hline 44 & -1.50 & -1.95 & 0.0 \\
\hline 45 & -1.50 & -1.95 & 0.0 \\
\hline 46 & -1.50 & -1.95 & 0.0 \\
\hline 47 & +1.84 & -1.95 & 0.0 \\
\hline 48 & +1.84 & -1.95 & 0.0 \\
\hline 49 & +1.84 & -1.95 & 0.0 \\
\hline 50 & +1.84 & -1.95 & 0.0 \\
\hline 51 & +1.84 & -1.95 & 0.0 \\
\hline 52 & +1.84 & -1.95 & 0.0 \\
\hline 53 & +1.84 & -1.95 & 0.0 \\
\hline 54 & +1.84 & -1.95 & 0.0 \\
\hline 55 & +1.84 & -1.95 & 0.0 \\
\hline 56 & +1.84 & -1.95 & 0.0 \\
\hline nlocxy & 50 & & \\
\hline 137 & $2 \quad 2.9400$ & $0-3.3530$ & \\
\hline 137 & $34 \quad 2.9400$ & D 3.3530 & \\
\hline 15 & $\begin{array}{ll}9 & -3.48\end{array}$ & -2.05 & \\
\hline 15 & $10 \quad-3.51$ & -1.82 & \\
\hline
\end{tabular}




$\begin{array}{rrrrr}1 & 5 & 11 & -3.50 & -1.62 \\ 1 & 5 & 12 & -3.47 & -1.40 \\ 1 & 5 & 13 & -3.42 & -1.18 \\ 1 & 5 & 14 & -3.35 & -0.98 \\ 1 & 5 & 15 & -3.25 & -0.76 \\ 1 & 5 & 16 & -3.13 & -0.55 \\ 1 & 5 & 17 & -2.91 & -0.28 \\ 1 & 5 & 18 & -2.60 & 0.0 \\ 1 & 6 & 18 & -2.46 & 0.0 \\ 1 & 7 & 18 & -2.35 & 0.0 \\ 1 & 8 & 18 & -2.23 & 0.0 \\ 1 & 9 & 18 & -2.10 & 0.0 \\ 1 & 10 & 18 & -1.99 & 0.0 \\ 1 & 11 & 18 & -1.88 & 0.0 \\ 1 & 12 & 18 & -1.69 & 0.0 \\ 1 & 13 & 18 & -1.50 & 0.0 \\ 1 & 5 & 19 & -2.91 & 0.28 \\ 1 & 5 & 20 & -3.13 & 0.55 \\ 1 & 5 & 21 & -3.25 & 0.76 \\ 1 & 5 & 22 & -3.35 & 0.98 \\ 1 & 5 & 23 & -3.42 & 1.18 \\ 1 & 5 & 24 & -3.47 & 1.40 \\ 1 & 5 & 25 & -3.50 & 1.62 \\ 1 & 5 & 26 & -3.51 & 1.82 \\ 1 & 5 & 27 & -3.48 & 2.05 \\ 1 & 37 & 8 & 3.60 & -2.22 \\ 1 & 37 & 9 & 3.60 & -2.02 \\ 1 & 37 & 10 & 3.60 & -1.83 \\ 1 & 37 & 11 & 3.60 & -1.64 \\ 1 & 37 & 12 & 3.60 & -1.42 \\ 1 & 37 & 13 & 3.60 & -1.22 \\ 1 & 37 & 14 & 3.60 & -1.01 \\ 1 & 37 & 15 & 3.60 & -0.78 \\ 1 & 37 & 16 & 3.60 & -0.53 \\ 1 & 37 & 17 & 3.60 & -0.27 \\ 1 & 37 & 18 & 3.60 & 0.0 \\ 1 & 37 & 19 & 3.60 & 0.27 \\ 1 & 37 & 20 & 3.60 & 0.53 \\ 1 & 37 & 21 & 3.60 & 0.78 \\ 1 & 37 & 22 & 3.60 & 1.01 \\ 1 & 37 & 23 & 3.60 & 1.22 \\ 1 & 37 & 24 & 3.60 & 1.42 \\ 1 & 37 & 25 & 3.60 & 1.64 \\ 1 & 37 & 26 & 3.60 & 1.83\end{array}$




\begin{tabular}{rrrrrr}
1 & 37 & 27 & 3.60 & 2.02 \\
1 & 37 & 28 & 3.60 & 2.22 \\
reshape & \multicolumn{2}{rr}{40} & & \\
23 & 20 & 5 & 5 & 1 & 0 \\
24 & 21 & 5 & 5 & 1 & 0 \\
25 & 22 & 5 & 5 & 1 & 0 \\
26 & 4 & 5 & 5 & 1 & 0 \\
20 & 17 & 2 & 2 & 0 & 0 \\
21 & 18 & 2 & 2 & 0 & 0 \\
22 & 19 & 2 & 2 & 0 & 0 \\
17 & 1 & 7 & 20 & 0 & 0 \\
18 & 2 & 3 & 20 & 0 & 0 \\
19 & 3 & 3 & 20 & 0 & 0 \\
33 & 30 & 5 & 5 & 1 & 0 \\
34 & 31 & 5 & 5 & 1 & 0 \\
35 & 32 & 5 & 5 & 1 & 0 \\
36 & 12 & 5 & 5 & 1 & 0 \\
30 & 27 & 2 & 2 & 0 & 0 \\
31 & 28 & 2 & 2 & 0 & 0 \\
32 & 29 & 2 & 2 & 0 & 0 \\
27 & 1 & 23 & 20 & 0 & 0 \\
28 & 2 & 19 & 20 & 0 & 0 \\
29 & 3 & 19 & 20 & 0 & 0 \\
43 & 40 & 5 & 5 & 1 & 0 \\
44 & 41 & 5 & 5 & 1 & 0 \\
45 & 42 & 5 & 5 & 1 & 0 \\
46 & 5 & 5 & 5 & 1 & 0 \\
40 & 37 & 2 & 2 & 0 & 0 \\
41 & 38 & 2 & 2 & 0 & 0 \\
42 & 39 & 2 & 2 & 0 & 0 \\
37 & 1 & 7 & 4 & 0 & 0 \\
38 & 2 & 3 & 4 & 0 & 0 \\
39 & 3 & 3 & 4 & 0 & 0 \\
53 & 50 & 5 & 5 & 1 & 0 \\
54 & 51 & 5 & 5 & 1 & 0 \\
55 & 52 & 5 & 5 & 1 & 0 \\
56 & 13 & 5 & 5 & 1 & 0 \\
50 & 47 & 2 & 2 & 0 & 0 \\
51 & 48 & 2 & 2 & 0 & 0 \\
52 & 49 & 2 & 2 & 0 & 0 \\
47 & 1 & 23 & 4 & 0 & 0 \\
48 & 2 & 19 & 4 & 0 & 0 \\
49 & 3 & 19 & 4 & 0 & 0 \\
straightx & 0 & & & \\
& & & & &
\end{tabular}




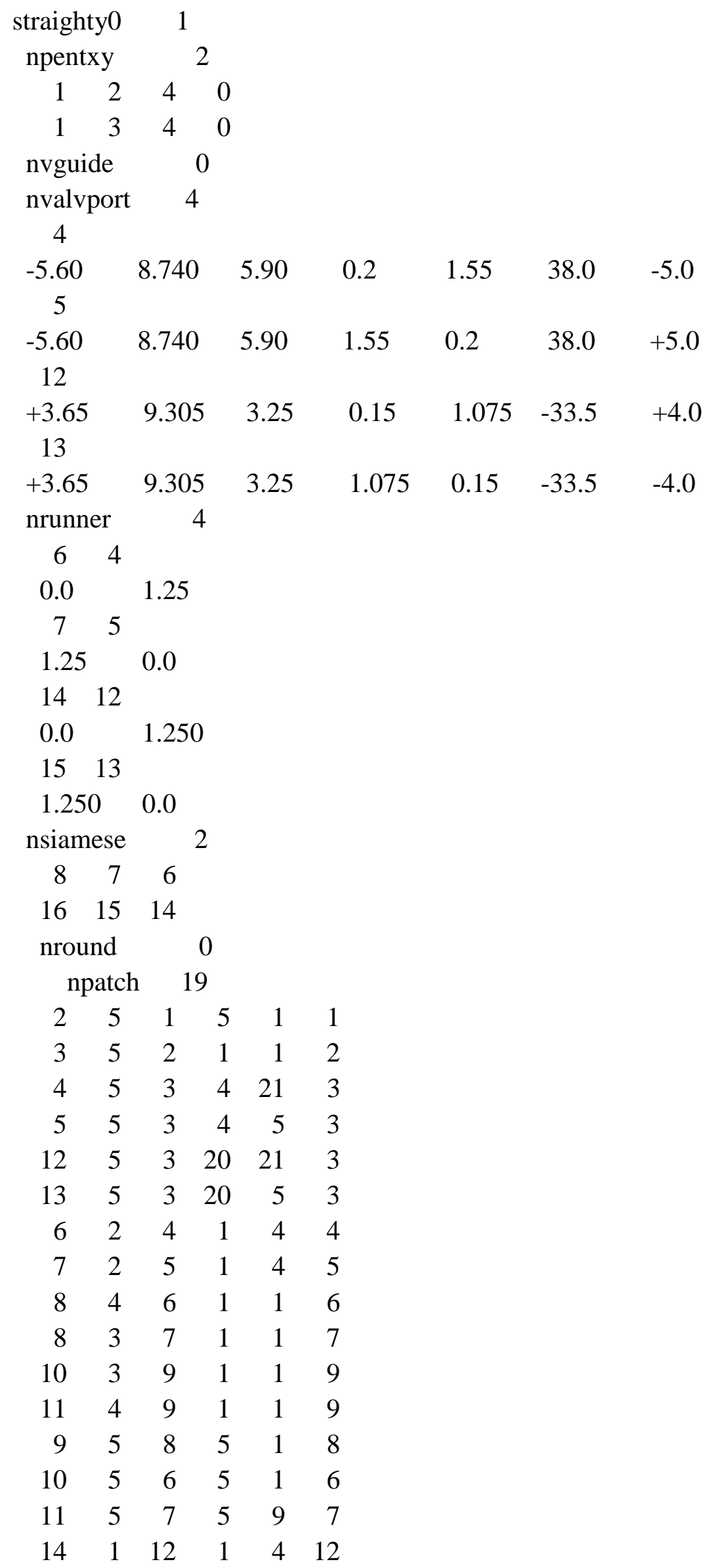




\begin{tabular}{cccccc}
15 & 1 & 13 & 1 & 4 & 13 \\
16 & 4 & 14 & 1 & 1 & 14 \\
16 & 3 & 15 & 1 & 1 & 15 \\
nrelaxb & 0 & & & \\
nprovtop & \multicolumn{2}{c}{4} & & \\
2 & 1 & 2 & 13 & 14 & \\
-1.5000 & 1.9500 & 1.6500 \\
0.35 & 1.0 & & \\
0.36 & 0.89 & & \\
0.38 & 0.80 & & \\
0.40 & 0.752 & & \\
0.45 & 0.665 & & \\
0.50 & 0.60 & & \\
0.55 & 0.545 & & \\
0.60 & 0.50 & & \\
0.65 & 0.47 & & \\
0.70 & 0.445 & & \\
0.75 & 0.42 & & \\
0.80 & 0.40 & & \\
1.65 & 0.15 & & & \\
1.8250 & 0.0 & & & \\
4 & 1 & 2 & 13 & 14 & \\
-1.5000 & -1.9500 & 1.6500 \\
0.35 & 1.0 & & \\
0.36 & 0.89 & & \\
0.38 & 0.80 & & \\
0.40 & 0.752 & & \\
0.45 & 0.665 & & \\
0.50 & 0.60 & & \\
0.55 & 0.545 & & \\
0.60 & 0.50 & & \\
0.65 & 0.47 & & \\
0.70 & 0.445 & & \\
0.75 & 0.42 & & \\
0.80 & 0.40 & & \\
1.65 & 0.15 & & & \\
1.8250 & 0.0 & & & \\
6 & 1 & 2 & 13 & 13 & \\
1.8400 & 1.9500 & 1.3500 \\
0.35 & 1.1 & & \\
0.40 & 0.95 & & \\
0.45 & 0.82 & & \\
0.50 & 0.73 & & \\
0.60 & 0.61 & & \\
& & &
\end{tabular}




\begin{tabular}{|c|c|}
\hline 0.70 & 0.51 \\
\hline 0.80 & 0.44 \\
\hline 0.90 & 0.38 \\
\hline 1.0 & 0.33 \\
\hline 1.10 & 0.29 \\
\hline 1.20 & 0.26 \\
\hline 1.35 & 0.22 \\
\hline 1.5750 & 0.0 \\
\hline $8 \quad 1$ & $\begin{array}{lll}2 & 13 & 13\end{array}$ \\
\hline $1.8400-1$ & $-1.9500 \quad 1.3500$ \\
\hline 0.35 & 1.1 \\
\hline 0.40 & 0.95 \\
\hline 0.45 & 0.82 \\
\hline 0.50 & 0.73 \\
\hline 0.60 & 0.61 \\
\hline 0.70 & 0.51 \\
\hline 0.80 & 0.44 \\
\hline 0.90 & 0.38 \\
\hline 1.0 & 0.33 \\
\hline 1.10 & 0.29 \\
\hline 1.20 & 0.26 \\
\hline 1.35 & 0.22 \\
\hline 1.5750 & 0.0 \\
\hline nprovfce & 0 \\
\hline nzcylwall & 21 \\
\hline 0.0 & \\
\hline 0.6385 & \\
\hline 1.2771 & \\
\hline 1.9156 & \\
\hline 2.5542 & \\
\hline 3.1927 & \\
\hline 3.8313 & \\
\hline 4.4698 & \\
\hline 5.1083 & \\
\hline 5.7469 & \\
\hline 6.3854 & \\
\hline 7.0240 & \\
\hline 7.6625 & \\
\hline 7.82234 & \\
\hline 7.98218 & \\
\hline 8.14202 & \\
\hline 8.30186 & \\
\hline 8.4617 & \\
\hline 8.53833 & \\
\hline
\end{tabular}




\begin{tabular}{llll}
8.57666 & & & \\
8.615 & & & \\
tilt & 2 & & \\
4 & & & \\
3 & +4.10 & 8.615 & +22.0 \\
2 & -3.75 & 8.615 & -20.0 \\
ndish & \multicolumn{2}{c}{1} & \\
0.45 & 3.2 & & 6.690 \\
nscallop & 0 & & \\
xoffset & 0.0 & & \\
yoffset & 0.0 & & \\
write17 & 1.0 & & \\
plotmesh & 1.0 & \\
xband & 0.1 & \\
yband & 0.15 & \\
zband & 0.01 & \\
nxplots & 2 & \\
-2.00 & & \\
+2.50 & & \\
nyplots & 2 & \\
0.0 & & \\
1.95 & & \\
nzplots & 1 & \\
0.0 & & \\
nvhide & 2 & & \\
45.0 & 75.0 & 5.0 \\
225.0 & 115.0 & 5.0 \\
& &
\end{tabular}




\section{Appendix B-ITAPE5}

K122298 4-valve pentroof engine example, (082996), 052899

\begin{tabular}{lc} 
irest & \multicolumn{1}{c}{0} \\
nohydro & \multicolumn{1}{c}{0} \\
lwall & 1 \\
lpr & 0 \\
irez & 4 \\
ncfilm & 9999 \\
nctap8 & 50 \\
nclast 9999 \\
ncmon & 25 \\
ncaspec & 20
\end{tabular}

$-27.0,-15.0,0.0,15.0,30.0,60.0,103.0,180.0,216.0$,

$270.0,345.0,360.0,365.0,370.0,375.0,380.0,450.0,540.0,609.0,720.0$

gmv $\quad 1.0$

cafilm $\quad 9.99 \mathrm{e}+9$

cafin $\quad 720.0$

angmom $\quad 0.0$

pgssw $\quad 0.0$

dti $\quad 1.00000 \mathrm{e}-5$

dtmxca 1.0

dtmax $1.00000 \mathrm{e}-3$

tlimd $\quad 1.0$

twfilm $\quad 9.99 \mathrm{e}+9$

twfin $\quad 9.99 \mathrm{e}+9$

fchsp $\quad 0.25$

bore $\quad 9.2$

stroke $\quad 8.5$

squish $\quad 0.115$

rpm $\quad 1.5 \mathrm{e}+3$

atdc $\quad-10.0$

datdct $\quad 0.0$

revrep 2.0

conrod 14.7

swirl $\quad 0.0$

swipro $\quad 3.11$

thsect 360.0

sector $\quad 0.0$

deact $\quad 0.0$

epsy $1.0 \mathrm{e}-3$

epsv $\quad 1.0 \mathrm{e}-3$

epsp $\quad 1.0 \mathrm{e}-4$

epst 1.0e-3 


\begin{tabular}{|c|c|}
\hline epsk & $1.0 \mathrm{e}$ \\
\hline epse & $1.0 \mathrm{e}-3$ \\
\hline $\mathrm{gx}$ & 0.0 \\
\hline gy & 0.0 \\
\hline O & 0.0 \\
\hline tcylwl & 293.15 \\
\hline thead & 293.15 \\
\hline tpistn 2 & 293.15 \\
\hline pardon & 0.0 \\
\hline $\mathrm{a} 0$ & 0.0 \\
\hline b0 & 1.0 \\
\hline artvis & 0.0 \\
\hline ecnsrv & 0.0 \\
\hline adia & 0.0 \\
\hline anu0 & 0.0 \\
\hline visrat-.66 & 56666667 \\
\hline tcut & 800.0 \\
\hline tcute 10 & 1000.0 \\
\hline epschm & 0.02 \\
\hline omgchm & 1.0 \\
\hline turbsw & 1.0 \\
\hline sgsl & 0.0 \\
\hline trbchem & 0.0 \\
\hline capa & 18.0 \\
\hline pmplict & 0.0 \\
\hline lospeed & 0.0 \\
\hline airmu1 & $1.457 \mathrm{e}-5$ \\
\hline airmu2 & 110.0 \\
\hline airla1 2 & 252.0 \\
\hline airla2 2 & 200.0 \\
\hline prl & 0.74 \\
\hline rpr & 1.11 \\
\hline rsc & 1.11 \\
\hline xignit & $1.0 \mathrm{e}+5$ \\
\hline tlign & -1 \\
\hline tdign & -1 \\
\hline calign & 346.5 \\
\hline cadign & 10.0 \\
\hline xignl1 & +0.1 \\
\hline xignr1 & +0.45 \\
\hline yignf1 & -0.25 \\
\hline yignd1 & +0.25 \\
\hline zignb1 & 9.5000 \\
\hline zignt1 & 9.9500 \\
\hline
\end{tabular}




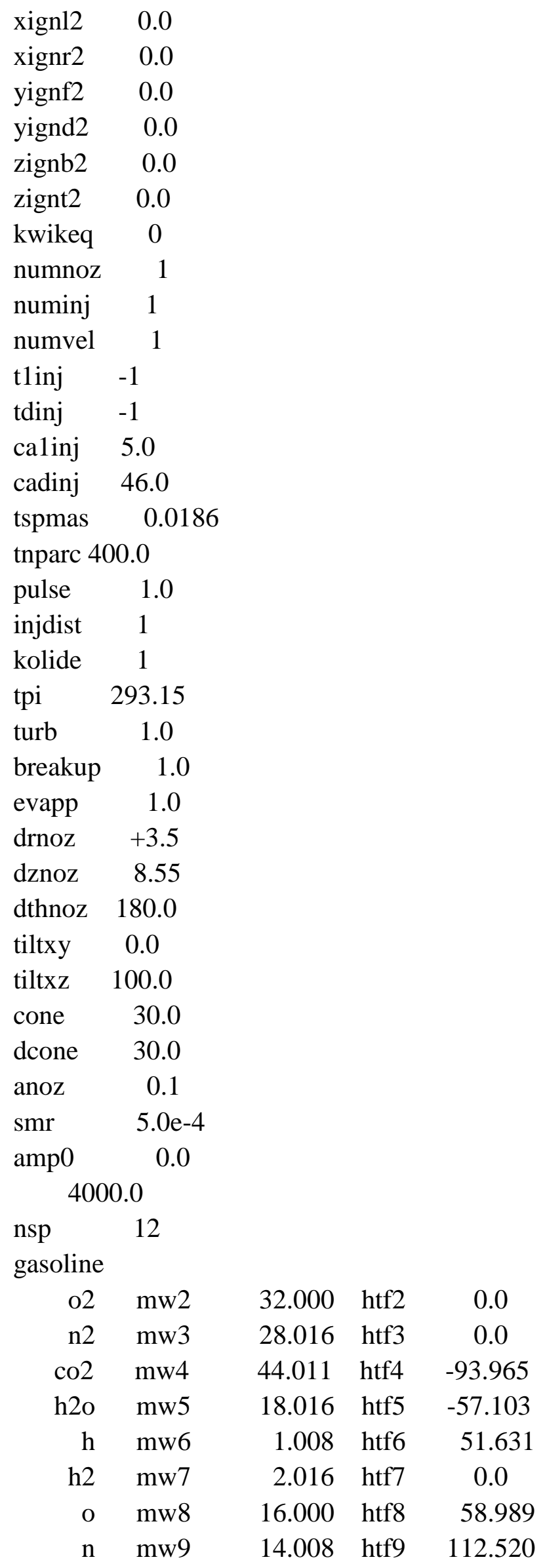




\begin{tabular}{|c|c|c|c|c|c|c|c|c|c|c|}
\hline & $\mathrm{mw}$ & & $17.008 \mathrm{~h}$ & htf10 & 9.289 & & & & & \\
\hline & $\mathrm{mw}$ & & $28.011 \mathrm{~h}$ & htf11 - & -27.200 & & & & & \\
\hline & $\mathrm{mw}$ & 12 & $30.008 \mathrm{~h}$ & htf12 & 21.456 & & & & & \\
\hline stoifu & 4.0 & & & & & & & & & \\
\hline stoio2 & 49. & & & & & & & & & \\
\hline nreg & 3 & & & & & & & & & \\
\hline presi, & $3 * c$ & $9.9000 \mathrm{e}$ & +5 & & & & & & & \\
\hline tempi & $3 * 2$ & 93.15 & & & & & & & & \\
\hline tkei, & $3 *($ & 0.10 & & & & & & & & \\
\hline scli, & $3 * c$ & 0.0 & & & & & & & & \\
\hline er, & $3 * 0$ & & & & & & & & & \\
\hline mfrac & $3 * 0$ & & & & & & & & & \\
\hline mfrac & $3 * 0$ & .22009 & 10204 & & & & & & & \\
\hline mfrac & $3 * 0$ & .76503 & 85386 & & & & & & & \\
\hline mfrac & $\operatorname{co} 2, \quad 3 * 9$ & .91386 & $3271 \mathrm{e}-3$ & & & & & & & \\
\hline mfrac & $\mathrm{h} 2 \mathrm{o}, \quad 3 * 4$ & 1.95657 & $7746 e-3$ & & & & & & & \\
\hline mfrac & $3 * 0$ & & & & & & & & & \\
\hline mfrac & $3 * 0$ & & & & & & & & & \\
\hline mfrac & $3 * 0$ & & & & & & & & & \\
\hline mfrac & $3 * 0$ & & & & & & & & & \\
\hline mfrac & $3 * 0$ & & & & & & & & & \\
\hline mfrac & $3 * 0$ & & & & & & & & & \\
\hline mfrac & $3 * 0$ & & & & & & & & & \\
\hline nrk & 4 & & & & & & & & & \\
\hline cf1 & $8.0000 \mathrm{e} 1$ & 0 ef1 & $1.5780 \mathrm{e}+$ & +4 zf1 & 0.0 & & & & & \\
\hline $\mathrm{cb} 1$ & 0.0 & eb1 & 0.0 & $\mathrm{zb} 1$ & 0.0 & & & & & \\
\hline am1 & 4 & 49 & 0 & 0 & 0 & 0 & 0 & 0 & 0 & 0 \\
\hline bm1 & 0 & 0 & 32 & 34 & 0 & 0 & 0 & 0 & 0 & 0 \\
\hline ae1 & 0.250 & 1.500 & 0.000 & 0.000 & 0.000 & 0.000 & & 0.000 & & 000 \\
\hline & 0.000 & 0.000 & 0.000 & 0.000 & & & & & & \\
\hline be1 & 0.000 & 0.000 & 0.000 & 0.000 & 0.000 & 0.000 & & 0.000 & & .000 \\
\hline & 0.000 & 0.000 & 0.000 & 0.000 & & & & & & \\
\hline $\mathrm{cf} 2$ & $1.5587 \mathrm{e} 1$ & 4 ef 2 & $6.7627 \mathrm{e}+$ & $+4 \mathrm{zf} 2$ & 0.0 & & & & & \\
\hline $\operatorname{cb} 2$ & $7.5000 \mathrm{e} 1$ & 2 eb2 & 0.0 & $\mathrm{zb} 2$ & 0.0 & & & & & \\
\hline $\operatorname{am} 2$ & 0 & 1 & 0 & 0 & 0 & 0 & 0 & 0 & 0 & 0 \\
\hline bm2 & 0 & 0 & 0 & 0 & 0 & 0 & 2 & 0 & 0 & 2 \\
\hline ae2 & 0.000 & 0.500 & 1.000 & 0.000 & 0.000 & 0.000 & & 0.000 & & 000 \\
\hline & 0.000 & 0.000 & 0.000 & 0.000 & & & & & & \\
\hline be 2 & 0.000 & 0.000 & 0.000 & 0.000 & 0.000 & 0.000 & & 0.000 & & .000 \\
\hline & 1.000 & 0.000 & 0.000 & 1.000 & & & & & & \\
\hline $\mathrm{cf} 3$ & $2.6484 \mathrm{e} 1$ & 0 ef3 & $5.9418 \mathrm{e}+$ & $+4 \mathrm{zf} 3$ & 1.0 & & & & & \\
\hline cb3 & $1.6000 \mathrm{e}-$ & -9 eb3 & $1.9678 \mathrm{e}$ & $e+4$ zb3 & 1.0 & & & & & \\
\hline $\operatorname{am} 3$ & 0 & 2 & 0 & 0 & 0 & 0 & 0 & 0 & 0 & 0 \\
\hline $\mathrm{bm} 3$ & 0 & 0 & 0 & 0 & 0 & 2 & 0 & 0 & 0 & 2 \\
\hline
\end{tabular}




\begin{tabular}{|c|c|c|c|c|c|c|c|c|c|c|}
\hline \multirow[t]{2}{*}{ ae3 } & 0.000 & 1.000 & 0.500 & 0.000 & 0.000 & \multicolumn{2}{|c|}{0.000} & 0.000 & \multicolumn{2}{|c|}{0.000} \\
\hline & 0.000 & 0.000 & 0.000 & 0.000 & & & & & & \\
\hline \multirow[t]{2}{*}{ be 3} & 0.000 & \multirow{2}{*}{$\begin{array}{l}0.000 \\
0.000\end{array}$} & 0.000 & 0.000 & 0.000 & \multicolumn{2}{|c|}{0.000} & \multirow[t]{2}{*}{0.000} & \multicolumn{2}{|c|}{1.000} \\
\hline & 0.000 & & 0.000 & 1.000 & & & & & & \\
\hline $\mathrm{cf} 4$ & \multicolumn{2}{|c|}{$2.1230 \mathrm{e} 14$ ef 4} & \multicolumn{2}{|l|}{$5.7020 \mathrm{e}+4 \mathrm{zf} 4$} & \multicolumn{6}{|l|}{0.0} \\
\hline $\operatorname{cb} 4$ & 0.0 & eb4 & 0.0 & $\mathrm{zb} 4$ & \multicolumn{2}{|c|}{0.0} & & \multirow[b]{2}{*}{2} & & \\
\hline am4 & 0 & 1 & 0 & 0 & 0 & 0 & 0 & & 0 & 0 \\
\hline bm4 & 0 & 0 & 0 & 2 & 0 & 0 & 0 & 0 & 0 & 2 \\
\hline ae4 & 0.000 & 0.000 & 0.500 & 00 & 0.000 & 0.0( & & 0.000 & 0.00 & \\
\hline & 0.000 & 1.000 & 0.000 & 00 & & & & & & \\
\hline be4 & 0.000 & 0.000 & 0.000 & 00 & 0.000 & 1.0 & & 0.000 & 0.00 & \\
\hline & 0.000 & 0.000 & 0.000 & 00 & & & & & & \\
\hline nre & 6 & & & & & & & & & \\
\hline as 1 & 0.990207 & bs1 & -51.7916 & $\operatorname{cs} 1$ & 0.9 & 3074 & ds 1 & & -0.343428 & es 1 \\
\hline 0.0111 & 568 & & & & & & & & & \\
\hline an1 & 0 & 0 & 0 & 0 & 1 & 0 & 0 & 0 & 0 & 0 \\
\hline bn 1 & 0 & 0 & 0 & 2 & 0 & 0 & 0 & 0 & 0 & 0 \\
\hline as2 & 0.431310 & bs2 & -59.6554 & $\operatorname{cs} 2$ & 3.5 & 3350 & $\mathrm{ds} 2$ & & -0.340016 & es2 \\
\hline 0.0158 & 715 & & & & & & & & & \\
\hline an2 & 1 & 0 & 0 & 0 & 0 & 0 & 0 & 0 & 0 & 0 \\
\hline bn 2 & 0 & 0 & 0 & 0 & 0 & 2 & 0 & 0 & 0 & 0 \\
\hline as3 & 0.794709 & bs3 & -113.2080 & $\operatorname{cs} 3$ & $3.1 \mathrm{C}$ & 8370 & ds3 & & -0.443814 & es3 \\
\hline 0.0269 & 599 & & & & & & & & & \\
\hline an3 & 0 & 1 & 0 & 0 & 0 & 0 & 0 & 0 & 0 & 0 \\
\hline bn3 & 0 & 0 & 0 & 0 & 0 & 0 & 2 & 0 & 0 & 0 \\
\hline as4 & -0.652939 & bs 4 & -9.8232 & $\operatorname{cs} 4$ & 3.93 & 0330 & ds4 & & 0.163490 & es4 \\
\hline-0.014 & 865 & & & & & & & & & \\
\hline an4 & 1 & 0 & 0 & 0 & 1 & 0 & 0 & 0 & 0 & 0 \\
\hline bn 4 & 0 & 0 & 0 & 0 & 0 & 0 & 0 & 2 & 0 & 0 \\
\hline as5 & 1.158882 & bs 5 & -76.8472 & $\operatorname{cs} 5$ & 8.5 & 2155 & ds 5 & & -0.868320 & es5 \\
\hline 0.0463 & 471 & & & & & & & & & \\
\hline an5 & 1 & 0 & 2 & 0 & 0 & 0 & 0 & 0 & 0 & 0 \\
\hline bn5 & 0 & 0 & 0 & 0 & 0 & 0 & 0 & 4 & 0 & 0 \\
\hline as6 & 0.980875 & bs6 & 68.4453 & $\operatorname{cs} 6$ & -10.5 & 938 & ds6 & & 0.574260 & es6 \\
\hline-0.041 & 570 & & & & & & & & & \\
\hline an6 & 1 & 0 & 0 & 0 & 0 & 0 & 0 & 0 & 2 & 0 \\
\hline bn6 & 0 & 0 & 0 & 0 & 0 & 0 & 0 & 0 & 0 & 0 \\
\hline nvalv & 4 & & & & & & & & & \\
\hline vliftm & 0.025 & & & & & & & & & \\
\hline skirttl & 0.1 & & & & & & & & & \\
\hline tmove & 293.15 & & & & & & & & & \\
\hline vtiltx & -20.0 & & & & & & & & & \\
\hline nlift & 139 & & & & & & & & & \\
\hline vliftm & 0.025 & & & & & & & & & \\
\hline
\end{tabular}




$\begin{array}{lc}\text { skirtth } & 0.1 \\ \text { tmove } & 293.15 \\ \text { vtiltxz } & -20.0 \\ \text { nlift } & 140 \\ \text { vliftmin } & 0.025 \\ \text { skirtth } & 0.1 \\ \text { tmove } & 293.15 \\ \text { vtiltxz } & +22.0 \\ \text { nlift } & 140 \\ \text { vliftmin } & 0.025 \\ \text { skirtth } & 0.1 \\ \text { tmove } & 293.15 \\ \text { vtiltxz } & +22.0 \\ \text { nlift } & 139 \\ \text { isoot } & 0 \\ \text { distamb } & 2.0 \\ \text { pamb } & 9.9000 \mathrm{e}+5 \\ \text { tkeamb } & 423.0 \\ \text { sclamb } & 4.8 \\ \text { velin } & 0.0 \\ \text { reedin } & 0.0 \\ \text { reedout } & 0.0 \\ \text { nregin0 } & 2 \\ \text { nregamb } & 3 \\ \text { numpcc } & 2 \\ 0.0 & 9.9000 \mathrm{e}+5 \\ 720.0 & 9.9000 \mathrm{e}+5 \\ \text { numpex } & 2 \\ 0.0 & 9.9000 \mathrm{e}+5 \\ 720.0 & 9.9000 \mathrm{e}+5 \\ & \end{array}$




\section{Appendix C-ITAPE18}

$0, \quad 0.1112360000000003$

$2, \quad 0.1325159999999999$

4, 0.1549999999999994

$6, \quad 0.1784680000000005$

$8, \quad 0.2027220000000005$

$10, \quad 0.2275840000000002$

$12, \quad 0.2528970000000008$

$14, \quad 0.2785200000000003$

$16, \quad 0.3043310000000012$

$18, \quad 0.3302200000000006$

$20, \quad 0.3560929999999995$

$22, \quad 0.3818640000000002$

$24, \quad 0.4074590000000011$

$26, \quad 0.4328110000000009$

$28, \quad 0.4578630000000015$

$30, \quad 0.4825619999999997$

$32, \quad 0.5068610000000007$

$34, \quad 0.5307189999999977$

$36, \quad 0.5540999999999983$

$38, \quad 0.5769710000000003$

$40, \quad 0.5993020000000016$

$42, \quad 0.621067$

$44, \quad 0.6422430000000006$

$46, \quad 0.6628089999999993$

$48, \quad 0.6827469999999991$

$50, \quad 0.7020400000000002$

$52, \quad 0.7206729999999979$

$54, \quad 0.7386349999999986$

$56, \quad 0.7559120000000021$

$58, \quad 0.7724970000000013$

$60, \quad 0.7883780000000016$

$62, \quad 0.8035500000000013$

$64, \quad 0.8180049999999994$

$66, \quad 0.8317380000000014$

$68, \quad 0.8447450000000032$

$70, \quad 0.8570200000000021$

$72, \quad 0.8685609999999997$

$74, \quad 0.8793650000000035$

$76, \quad 0.8894290000000034$

$78, \quad 0.8987520000000018$

$80, \quad 0.9073320000000038$

$82, \quad 0.9151680000000013$ 
$84, \quad 0.9222600000000014$

$86, \quad 0.928605000000001$

$88, \quad 0.9342049999999986$

$90, \quad 0.9390590000000003$

$92, \quad 0.9431650000000005$

$94, \quad 0.9465260000000022$

$96, \quad 0.9491390000000024$

$98, \quad 0.9510070000000006$

$100, \quad 0.9521270000000044$

$102, \quad 0.9525000000000006$

$104, \quad 0.9521270000000044$

$106, \quad 0.9510070000000006$

$108, \quad 0.9491390000000024$

$110, \quad 0.9465260000000022$

$112, \quad 0.9431650000000005$

$114, \quad 0.9390590000000003$

$116, \quad 0.9342049999999986$

$118, \quad 0.928605000000001$

$120, \quad 0.9222600000000014$

$122, \quad 0.9151680000000013$

$124, \quad 0.9073330000000013$

$126, \quad 0.8987529999999992$

$128, \quad 0.8894300000000008$

$130, \quad 0.879366000000001$

$132, \quad 0.8685639999999992$

$134, \quad 0.8570240000000027$

$136, \quad 0.8447500000000012$

$138, \quad 0.831745999999999$

$140, \quad 0.8180160000000001$

$142, \quad 0.803564999999999$

$144, \quad 0.7883980000000008$

$146, \quad 0.7725229999999996$

$148, \quad 0.755946999999999$

$150, \quad 0.7386789999999976$

$152, \quad 0.7207299999999996$

$154, \quad 0.7021119999999996$

$156, \quad 0.6828369999999993$

$158, \quad 0.6629210000000008$

$160, \quad 0.6423810000000003$

$162, \quad 0.6212359999999997$

$164, \quad 0.5995080000000002$

$166, \quad 0.5772200000000005$

$168, \quad 0.5544000000000011$

$170, \quad 0.5310780000000008$ 
$172, \quad 0.507286999999998$

$174, \quad 0.4830670000000001$

$176, \quad 0.4584580000000003$

$178, \quad 0.4335080000000016$

$180, \quad 0.4082730000000012$

$182, \quad 0.382810000000001$

$184, \quad 0.357187999999999$

$186, \quad 0.3314839999999997$

$188, \quad 0.3057839999999992$

$190, \quad 0.2801849999999995$

$192, \quad 0.2547979999999992$

$194, \quad 0.229749$

196, 0.2051780000000001

198, 0.1812459999999998

200, 0.1581330000000003

$202, \quad 0.1360399999999995$

$204, \quad 0.115186$

206, 9.580799999999989E-2

208, 7.814999999999994E-2

$210, \quad 6.245000000000011 \mathrm{E}-2$

$212, \quad 4.891400000000012 \mathrm{E}-2$

$214, \quad 3.767900000000001 \mathrm{E}-2$

$216, \quad 2.877200000000002 \mathrm{E}-2$

$218, \quad 2.205899999999994 \mathrm{E}-2$

$220, \quad 1.722200000000007 \mathrm{E}-2$

$222, \quad 1.378400000000001 \mathrm{E}-2$

$224, \quad 1.122999999999996 \mathrm{E}-2$

226, 9.191000000000004E-3

$228, \quad 7.473000000000035 \mathrm{E}-3$

230, 5.942000000000002E-3

$232, \quad 4.518999999999995 \mathrm{E}-3$

$234, \quad 3.197000000000005 \mathrm{E}-3$

$236, \quad 2.031000000000005 \mathrm{E}-3$

$238, \quad 1.098000000000001 \mathrm{E}-3$

$240, \quad 4.59000000000001 \mathrm{E}-4$

$242, \quad 1.18 \mathrm{E}-4$

$244, \quad 8.000000000000031 \mathrm{E}-6$

$246, \quad 6.776260000000019 \mathrm{E}-22$

$692, \quad 4.000000000000015 \mathrm{E}-6$

$694, \quad 1.130000000000002 \mathrm{E}-4$

$696, \quad 5.230000000000026 \mathrm{E}-4$

$698, \quad 1.434000000000004 \mathrm{E}-3$

$700, \quad 3.047999999999995 \mathrm{E}-3$

$702, \quad 5.564999999999986 \mathrm{E}-3$ 
$704, \quad 9.245000000000003 \mathrm{E}-3$

$706, \quad 1.448900000000003 \mathrm{E}-2$

$708, \quad 2.169699999999996 \mathrm{E}-2$

$710, \quad 3.114399999999995 \mathrm{E}-2$

$712, \quad 4.293300000000011 \mathrm{E}-2$

$714, \quad 5.701700000000009 \mathrm{E}-2$

$716, \quad 7.324200000000002 \mathrm{E}-2$

$718, \quad 9.139600000000003 \mathrm{E}-2$

$720, \quad 0.1112360000000003$

$0, \quad 0.1042009999999998$

$2, \quad 0.1240459999999999$

4, 0.1454509999999996

$6, \quad 0.1681989999999995$

$8, \quad 0.1920769999999994$

$10, \quad 0.2168679999999998$

$12, \quad 0.2423720000000005$

$14, \quad 0.2683920000000004$

$16, \quad 0.294751999999999$

$18, \quad 0.321295000000001$

$20, \quad 0.3478840000000005$

$22, \quad 0.3743909999999993$

$24, \quad 0.4007180000000012$

$26, \quad 0.4267710000000005$

$28, \quad 0.452475999999999$

$30, \quad 0.4777740000000001$

$32, \quad 0.5026080000000022$

$34, \quad 0.5269359999999992$

$36, \quad 0.5507229999999979$

$38, \quad 0.5739380000000018$

$40, \quad 0.5965600000000002$

$42, \quad 0.6185660000000013$

$44, \quad 0.6399429999999988$

$46, \quad 0.6606719999999981$

$48, \quad 0.6807429999999997$

$50, \quad 0.7001479999999987$

$52, \quad 0.7188760000000016$

$54, \quad 0.7369200000000014$

$56, \quad 0.7542709999999992$

$58, \quad 0.7709259999999993$

$60, \quad 0.7868870000000001$

$62, \quad 0.8021190000000011$

$64, \quad 0.8166480000000007$

$66, \quad 0.8304580000000001$

$68, \quad 0.8435470000000009$ 
$70, \quad 0.855909000000004$

$72, \quad 0.8675390000000007$

$74, \quad 0.8784360000000007$

$76, \quad 0.8885960000000033$

$78, \quad 0.8980150000000009$

$80, \quad 0.9066910000000021$

$82, \quad 0.9146210000000004$

$84, \quad 0.9218039999999981$

$86, \quad 0.9282350000000044$

$88, \quad 0.9339150000000025$

$90, \quad 0.9388420000000011$

$92, \quad 0.9430130000000041$

$94, \quad 0.9464269999999999$

96, 0.9490839999999992

$98, \quad 0.9509810000000023$

$100, \quad 0.9521210000000018$

$102, \quad 0.9525000000000006$

$104, \quad 0.9521210000000018$

$106, \quad 0.9509810000000023$

108, 0.9490839999999992

$110, \quad 0.9464269999999999$

$112, \quad 0.9430130000000041$

$114, \quad 0.9388420000000011$

$116, \quad 0.9339170000000045$

$118, \quad 0.9282380000000003$

$120, \quad 0.9218070000000012$

$122, \quad 0.9146239999999999$

124, 0.9066940000000017

$126, \quad 0.8980200000000025$

$128, \quad 0.8886010000000013$

$130, \quad 0.8784460000000038$

$132, \quad 0.8675520000000034$

$134, \quad 0.8559240000000017$

$136, \quad 0.8435670000000037$

$138, \quad 0.8304860000000041$

$140, \quad 0.8166810000000027$

$142, \quad 0.8021600000000007$

$144, \quad 0.7869250000000001$

$146, \quad 0.7709840000000021$

$148, \quad 0.7543420000000012$

$150, \quad 0.7370009999999994$

$152, \quad 0.7189720000000008$

$154, \quad 0.7002629999999996$

$156, \quad 0.6808770000000024$ 
$158, \quad 0.6608270000000012$

$160, \quad 0.6401210000000006$

$162, \quad 0.6187719999999999$

$164, \quad 0.5967929999999981$

$166, \quad 0.5742049999999992$

$168, \quad 0.5510250000000028$

$170, \quad 0.5272790000000001$

$172, \quad 0.5029959999999996$

$174, \quad 0.4782109999999999$

$176, \quad 0.4529730000000001$

$178, \quad 0.4273300000000013$

$180, \quad 0.4013479999999987$

$182, \quad 0.375102$

$184, \quad 0.3486840000000004$

$186, \quad 0.3221990000000012$

$188, \quad 0.295770000000001$

$190, \quad 0.269540000000001$

$192, \quad 0.2436700000000007$

$194, \quad 0.2183359999999999$

196, 0.1937329999999999

$198, \quad 0.1700759999999999$

200, 0.1475720000000003

$202, \quad 0.1264440000000002$

204, 0.1068959999999999

206, 8.911839999999982E-2

$208, \quad 7.325610000000004 \mathrm{E}-2$

$210, \quad 5.941060000000009 \mathrm{E}-2$

212, 4.761989999999993E-2

$214, \quad 3.783840000000005 \mathrm{E}-2$

$216, \quad 2.994660000000015 \mathrm{E}-2$

$218, \quad 2.373630000000004 \mathrm{E}-2$

220, $\quad 1.894079999999998 \mathrm{E}-2$

$222, \quad 1.52679 \mathrm{E}-2$

$224, \quad 1.24206 \mathrm{E}-2$

$226, \quad 1.016 \mathrm{E}-2$

$228, \quad 8.300719999999983 \mathrm{E}-3$

$230, \quad 6.690360000000006 \mathrm{E}-3$

$232, \quad 5.219699999999993 \mathrm{E}-3$

234, 3.843020000000016E-3

$236, \quad 2.590800000000004 \mathrm{E}-3$

$238, \quad 1.531619999999997 \mathrm{E}-3$

$240, \quad 7.391399999999992 \mathrm{E}-4$

$242, \quad 2.540000000000007 \mathrm{E}-4$

$244, \quad 4.063999999999999 \mathrm{E}-5$ 
$688, \quad 1.778 \mathrm{E}-5$

$690, \quad 1.4224 \mathrm{E}-4$

$692, \quad 4.749799999999998 \mathrm{E}-4$

$694, \quad 1.127759999999998 \mathrm{E}-3$

$696, \quad 2.204720000000007 \mathrm{E}-3$

$698, \quad 3.810000000000007 \mathrm{E}-3$

$700, \quad 6.050280000000019 \mathrm{E}-3$

$702, \quad 9.057639999999977 \mathrm{E}-3$

$704, \quad 1.302000000000003 \mathrm{E}-2$

$706, \quad 1.818390000000003 \mathrm{E}-2$

$708, \quad 2.481330000000003 \mathrm{E}-2$

$710, \quad 3.314949999999994 \mathrm{E}-2$

$712, \quad 4.337049999999997 \mathrm{E}-2$

$714, \quad 5.558790000000013 \mathrm{E}-2$

$716, \quad 6.983479999999975 \mathrm{E}-2$

$718, \quad 8.607039999999965 \mathrm{E}-2$

$720, \quad 0.1042009999999998$

$0, \quad 2.994660000000015 \mathrm{E}-2$

$2, \quad 2.373630000000004 \mathrm{E}-2$

4, 1.894079999999998E-2

$6, \quad 1.52679 \mathrm{E}-2$

$8, \quad 1.24206 \mathrm{E}-2$

$10, \quad 1.016 \mathrm{E}-2$

$12, \quad 8.300719999999983 \mathrm{E}-3$

$14, \quad 6.690360000000006 \mathrm{E}-3$

$16, \quad 5.219699999999993 \mathrm{E}-3$

$18, \quad 3.843020000000016 \mathrm{E}-3$

$20, \quad 2.590800000000004 \mathrm{E}-3$

$22, \quad 1.531619999999997 \mathrm{E}-3$

24, 7.391399999999992E-4

$26, \quad 2.540000000000007 \mathrm{E}-4$

$28, \quad 4.063999999999999 \mathrm{E}-5$

$472, \quad 1.778 \mathrm{E}-5$

$474, \quad 1.4224 \mathrm{E}-4$

$476, \quad 4.749799999999998 \mathrm{E}-4$

$478, \quad 1.127759999999998 \mathrm{E}-3$

$480, \quad 2.204720000000007 \mathrm{E}-3$

$482, \quad 3.810000000000007 \mathrm{E}-3$

$484, \quad 6.050280000000019 \mathrm{E}-3$

$486, \quad 9.057639999999977 \mathrm{E}-3$

$488, \quad 1.302000000000003 \mathrm{E}-2$

$490, \quad 1.818390000000003 \mathrm{E}-2$

$492, \quad 2.481330000000003 \mathrm{E}-2$

$494, \quad 3.314949999999994 \mathrm{E}-2$ 
$496, \quad 4.337049999999997 \mathrm{E}-2$

$498, \quad 5.558790000000013 \mathrm{E}-2$

$500, \quad 6.983479999999975 \mathrm{E}-2$

$502, \quad 8.607039999999965 \mathrm{E}-2$

$504, \quad 0.1042009999999998$

$506, \quad 0.1240459999999999$

$508, \quad 0.1454509999999996$

$510, \quad 0.1681989999999995$

$512, \quad 0.1920769999999994$

$514, \quad 0.2168679999999998$

$516, \quad 0.2423720000000005$

$518, \quad 0.2683920000000004$

$520, \quad 0.294751999999999$

$522, \quad 0.321295000000001$

$524, \quad 0.3478840000000005$

$526, \quad 0.3743909999999993$

$528, \quad 0.4007180000000012$

$530, \quad 0.4267710000000005$

$532, \quad 0.452475999999999$

$534, \quad 0.4777740000000001$

$536, \quad 0.5026080000000022$

$538, \quad 0.5269359999999992$

$540, \quad 0.5507229999999979$

$542, \quad 0.5739380000000018$

$544, \quad 0.5965600000000002$

$546, \quad 0.6185660000000013$

$548, \quad 0.6399429999999988$

$550, \quad 0.6606719999999981$

$552, \quad 0.6807429999999997$

$554, \quad 0.7001479999999987$

$556, \quad 0.7188760000000016$

$558, \quad 0.7369200000000014$

$560, \quad 0.7542709999999992$

$562, \quad 0.7709259999999993$

$564, \quad 0.7868870000000001$

$566, \quad 0.8021190000000011$

$568, \quad 0.8166480000000007$

$570, \quad 0.8304580000000001$

$572, \quad 0.8435470000000009$

$574, \quad 0.855909000000004$

$576, \quad 0.8675390000000007$

$578, \quad 0.8784360000000007$

$580, \quad 0.8885960000000033$

$582, \quad 0.8980150000000009$ 
$584, \quad 0.9066910000000021$

$586, \quad 0.9146210000000004$

$588, \quad 0.9218039999999981$

$590, \quad 0.9282350000000044$

$592, \quad 0.9339150000000025$

$594, \quad 0.9388420000000011$

596, 0.9430130000000041

$598, \quad 0.9464269999999999$

$600, \quad 0.9490839999999992$

$602, \quad 0.9509810000000023$

$604, \quad 0.9521210000000018$

$606, \quad 0.9525000000000006$

$608, \quad 0.9521210000000018$

$610, \quad 0.9509810000000023$

$612, \quad 0.9490839999999992$

$614, \quad 0.9464269999999999$

$616, \quad 0.9430130000000041$

$618, \quad 0.9388420000000011$

$620, \quad 0.9339170000000045$

$622, \quad 0.9282380000000003$

$624, \quad 0.9218070000000012$

$626, \quad 0.9146239999999999$

$628, \quad 0.9066940000000017$

630, 0.8980200000000025

$632, \quad 0.8886010000000013$

634, 0.8784460000000038

$636, \quad 0.8675520000000034$

$638, \quad 0.8559240000000017$

$640, \quad 0.8435670000000037$

$642, \quad 0.8304860000000041$

644, 0.8166810000000027

$646, \quad 0.8021600000000007$

$648, \quad 0.7869250000000001$

$650, \quad 0.7709840000000021$

$652, \quad 0.7543420000000012$

$654, \quad 0.7370009999999994$

$656, \quad 0.7189720000000008$

$658, \quad 0.7002629999999996$

$660, \quad 0.6808770000000024$

$662, \quad 0.6608270000000012$

$664,0.6401210000000006$

666, 0.6187719999999999

$668, \quad 0.5967929999999981$

$670, \quad 0.5742049999999992$ 
$672, \quad 0.5510250000000028$

$674, \quad 0.5272790000000001$

$676, \quad 0.5029959999999996$

$678, \quad 0.4782109999999999$

$680, \quad 0.4529730000000001$

$682, \quad 0.4273300000000013$

$684, \quad 0.4013479999999987$

$686, \quad 0.375102$

$688, \quad 0.3486840000000004$

$690, \quad 0.3221990000000012$

$692, \quad 0.295770000000001$

$694, \quad 0.269540000000001$

$696, \quad 0.2436700000000007$

$698, \quad 0.2183359999999999$

$700, \quad 0.1937329999999999$

$702, \quad 0.1700759999999999$

$704, \quad 0.1475720000000003$

$706, \quad 0.1264440000000002$

$708, \quad 0.1068959999999999$

$710, \quad 8.911839999999982 \mathrm{E}-2$

$712, \quad 7.325610000000004 \mathrm{E}-2$

$714, \quad 5.941060000000009 \mathrm{E}-2$

$716, \quad 4.761989999999993 \mathrm{E}-2$

$718, \quad 3.783840000000005 \mathrm{E}-2$

$720, \quad 2.994660000000015 \mathrm{E}-2$

$0, \quad 3.767900000000001 \mathrm{E}-2$

$2, \quad 2.877200000000002 \mathrm{E}-2$

4, 2.205899999999994E-2

$6, \quad 1.722200000000007 \mathrm{E}-2$

$8, \quad 1.378400000000001 \mathrm{E}-2$

$10, \quad 1.122999999999996 \mathrm{E}-2$

$12, \quad 9.191000000000004 \mathrm{E}-3$

$14, \quad 7.473000000000035 \mathrm{E}-3$

$16, \quad 5.942000000000002 \mathrm{E}-3$

$18, \quad 4.518999999999995 \mathrm{E}-3$

$20, \quad 3.197000000000005 \mathrm{E}-3$

$22, \quad 2.031000000000005 \mathrm{E}-3$

$24, \quad 1.098000000000001 \mathrm{E}-3$

$26, \quad 4.59000000000001 \mathrm{E}-4$

$28, \quad 1.18 \mathrm{E}-4$

$30, \quad 8.000000000000031 \mathrm{E}-6$

$32, \quad 6.776260000000019 \mathrm{E}-22$

$478, \quad 4.000000000000015 \mathrm{E}-6$

$480, \quad 1.130000000000002 \mathrm{E}-4$ 
$482, \quad 5.230000000000026 \mathrm{E}-4$

$484, \quad 1.434000000000004 \mathrm{E}-3$

$486, \quad 3.047999999999995 \mathrm{E}-3$

$488, \quad 5.564999999999986 \mathrm{E}-3$

$490, \quad 9.245000000000003 \mathrm{E}-3$

$492, \quad 1.448900000000003 \mathrm{E}-2$

$494, \quad 2.169699999999996 \mathrm{E}-2$

496, 3.114399999999995E-2

$498, \quad 4.293300000000011 \mathrm{E}-2$

$500, \quad 5.701700000000009 \mathrm{E}-2$

$502, \quad 7.324200000000002 \mathrm{E}-2$

$504, \quad 9.139600000000003 \mathrm{E}-2$

$506, \quad 0.1112360000000003$

$508, \quad 0.1325159999999999$

$510, \quad 0.1549999999999994$

$512, \quad 0.1784680000000005$

$514, \quad 0.2027220000000005$

$516, \quad 0.2275840000000002$

$518, \quad 0.2528970000000008$

$520, \quad 0.2785200000000003$

$522, \quad 0.3043310000000012$

$524, \quad 0.3302200000000006$

$526, \quad 0.3560929999999995$

$528, \quad 0.3818640000000002$

$530, \quad 0.4074590000000011$

$532, \quad 0.4328110000000009$

$534, \quad 0.4578630000000015$

$536, \quad 0.4825619999999997$

$538, \quad 0.5068610000000007$

$540, \quad 0.5307189999999977$

$542, \quad 0.5540999999999983$

$544, \quad 0.5769710000000003$

$546, \quad 0.5993020000000016$

$548, \quad 0.621067$

$550, \quad 0.6422430000000006$

$552, \quad 0.6628089999999993$

$554, \quad 0.6827469999999991$

$556, \quad 0.7020400000000002$

$558, \quad 0.7206729999999979$

$560, \quad 0.7386349999999986$

$562, \quad 0.7559120000000021$

$564, \quad 0.7724970000000013$

$566, \quad 0.7883780000000016$

$568, \quad 0.8035500000000013$ 
$570, \quad 0.8180049999999994$

$572, \quad 0.8317380000000014$

$574, \quad 0.8447450000000032$

$576, \quad 0.8570200000000021$

$578, \quad 0.8685609999999997$

$580, \quad 0.8793650000000035$

$582, \quad 0.8894290000000034$

$584, \quad 0.8987520000000018$

586, 0.9073320000000038

$588, \quad 0.9151680000000013$

$590, \quad 0.9222600000000014$

$592, \quad 0.928605000000001$

594, 0.9342049999999986

$596, \quad 0.9390590000000003$

$598, \quad 0.9431650000000005$

$600, \quad 0.9465260000000022$

$602, \quad 0.9491390000000024$

$604,0.9510070000000006$

$606, \quad 0.9521270000000044$

$608, \quad 0.9525000000000006$

$610, \quad 0.9521270000000044$

$612, \quad 0.9510070000000006$

$614, \quad 0.9491390000000024$

$616, \quad 0.9465260000000022$

$618, \quad 0.9431650000000005$

$620, \quad 0.9390590000000003$

$622, \quad 0.9342049999999986$

$624, \quad 0.928605000000001$

$626, \quad 0.9222600000000014$

$628, \quad 0.9151680000000013$

$630, \quad 0.9073330000000013$

$632, \quad 0.8987529999999992$

$634, \quad 0.8894300000000008$

$636, \quad 0.879366000000001$

$638, \quad 0.8685639999999992$

$640, \quad 0.8570240000000027$

$642, \quad 0.8447500000000012$

$644, \quad 0.831745999999999$

$646, \quad 0.8180160000000001$

$648, \quad 0.803564999999999$

$650, \quad 0.7883980000000008$

$652, \quad 0.7725229999999996$

$654, \quad 0.755946999999999$

$656, \quad 0.7386789999999976$ 
$658, \quad 0.7207299999999996$

$660, \quad 0.7021119999999996$

$662, \quad 0.6828369999999993$

$664, \quad 0.6629210000000008$

$666, \quad 0.6423810000000003$

$668, \quad 0.6212359999999997$

$670, \quad 0.5995080000000002$

$672, \quad 0.5772200000000005$

$674, \quad 0.5544000000000011$

$676, \quad 0.5310780000000008$

$678, \quad 0.507286999999998$

$680, \quad 0.4830670000000001$

$682, \quad 0.4584580000000003$

$684, \quad 0.4335080000000016$

$686, \quad 0.4082730000000012$

$688, \quad 0.382810000000001$

$690, \quad 0.357187999999999$

$692, \quad 0.3314839999999997$

$694, \quad 0.3057839999999992$

$696, \quad 0.2801849999999995$

$698, \quad 0.2547979999999992$

$700, \quad 0.229749$

$702, \quad 0.2051780000000001$

$704, \quad 0.1812459999999998$

$706, \quad 0.1581330000000003$

$708, \quad 0.1360399999999995$

$710, \quad 0.115186$

$712, \quad 9.580799999999989 \mathrm{E}-2$

$714, \quad 7.814999999999994 \mathrm{E}-2$

$716, \quad 6.245000000000011 \mathrm{E}-2$

$718, \quad 4.891400000000012 \mathrm{E}-2$

$720, \quad 3.767900000000001 \mathrm{E}-2$ 


\section{References}

[1] KIVA-II: A computer Program for Chemically Reactive Flows with Spray. A. A. Amsden, P. J. 0'Rouke and T. D. Butler.

[2] KIVA-3V: A Block-Structure KIVA Program for Engines with Vertical or Canted Valves. Los Alamos.

[3] KIVA-3V, RELEASE 2, IMPROVEMENTS TO KIVA-3V. Anthony A. Amsden, $\mathrm{T}-3$.

[4] Internal Combustion Engine Fundamentals. John B. Heywood. 